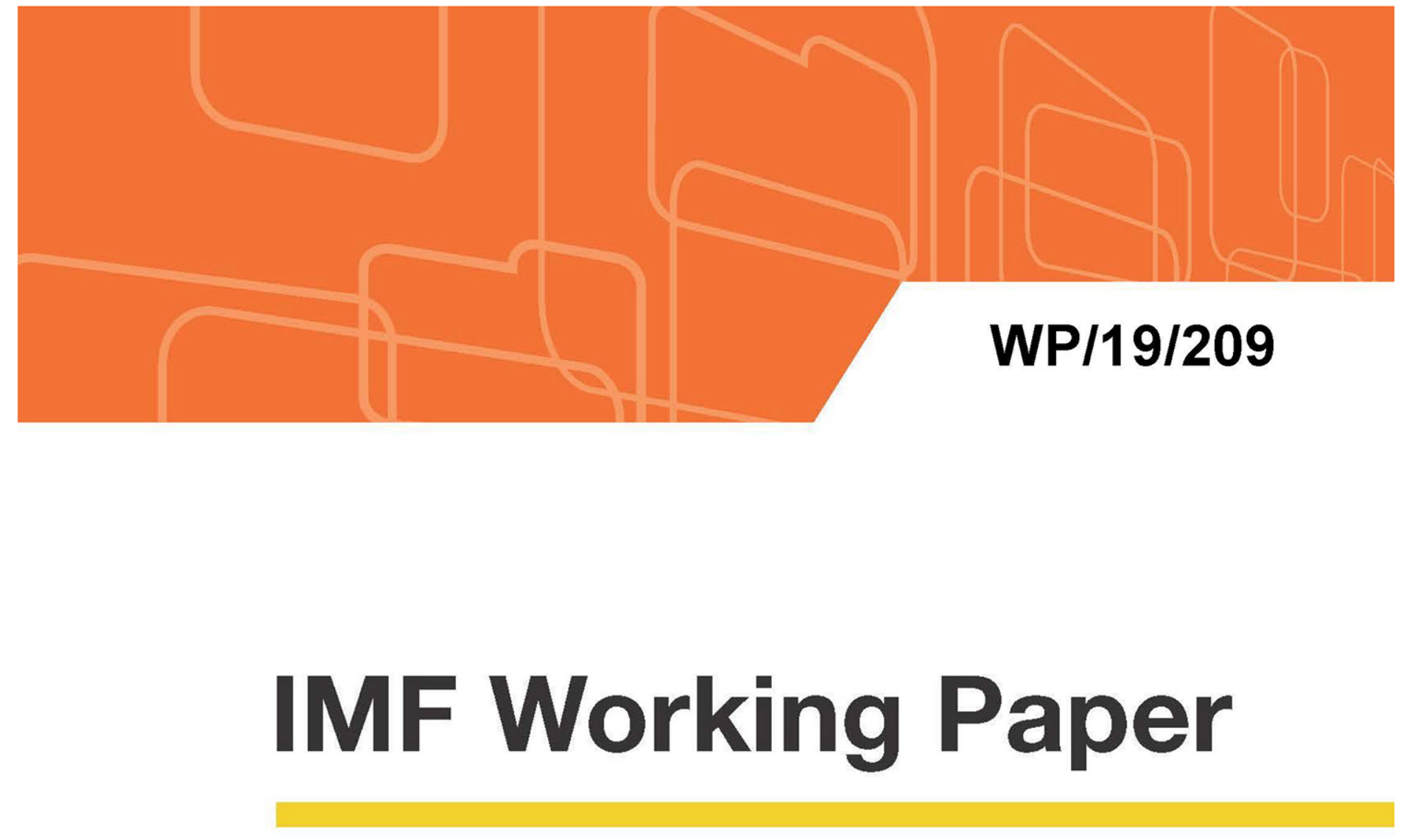

\title{
SME Financial Inclusion for Sustained Growth in the Middle East and Central Asia
}

by Mishel Ghassibe, Maximiliano Appendino and Samir Elsadek Mahmoudi

IMF Working Papers describe research in progress by the author(s) and are publis hed to elicit comments and to encourage debate. The views expressed in IMF Working Papers are those of the author(s) and do not necessarily represent the views of the IMF, its Executive Board, or IMF management.

$$
\text { I N T E R N A T I O N A L M O N E T A R Y F U N D }
$$




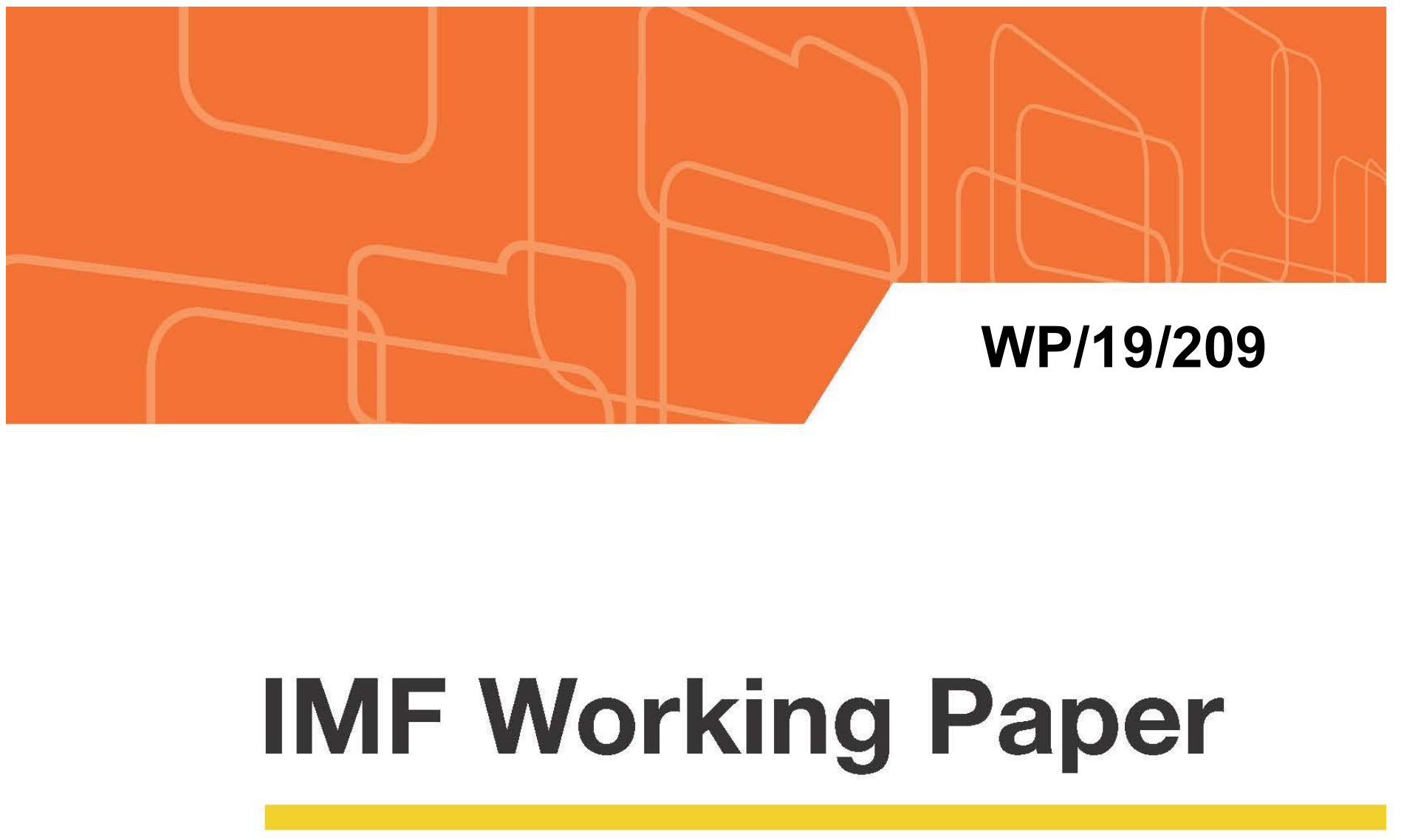

\section{SME Financial Inclusion for Sustained Growth in the Middle East and Central Asia}

by Mishel Ghassibe, Maximiliano Appendino and Samir Elsadek Mahmoudi

IMF Working Papers describe re search in progress by the author(s) and are publis hed to e licit comments and to encourage de bate.

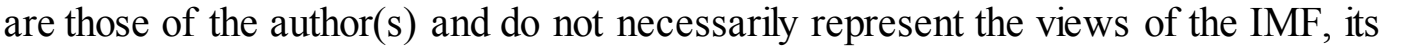

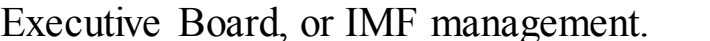

$$
\text { I N T E R N A T I O N A L M O N E T A R Y F U N D }
$$




\title{
IMF Working Paper
}

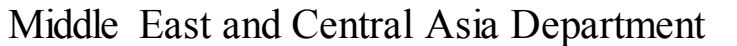

SME Financial Inclusion for Sustained Growth in the

Middle East and Central Asia

Prepared by Mis hel Ghassibe, Maximiliano Appendino and Samir Elsadek Mahmoudi

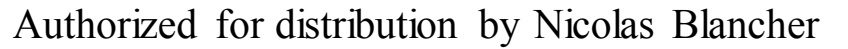

September $\square\|\| \square$

IMF Working Papers des cribe research in progress by the author(s) and are published to

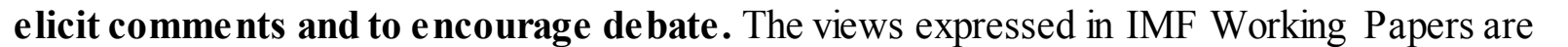
पा।

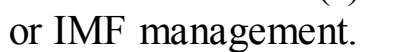

\begin{abstract}

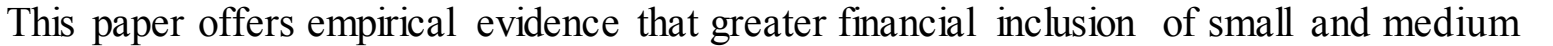

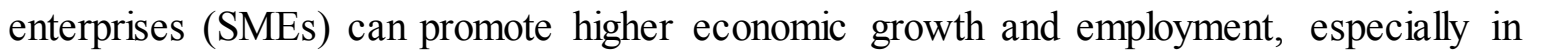

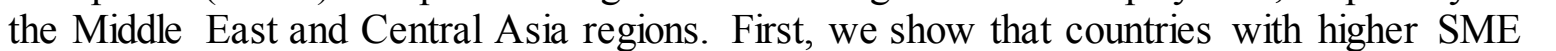

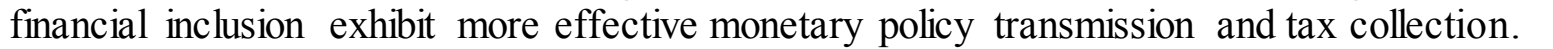

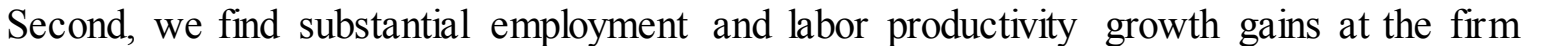

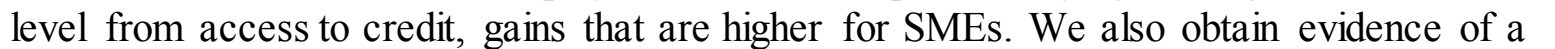

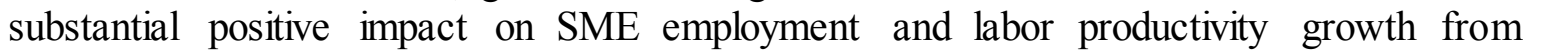
प

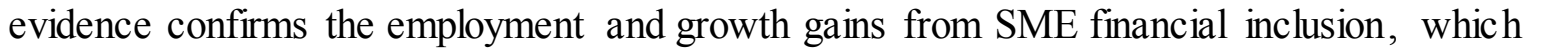

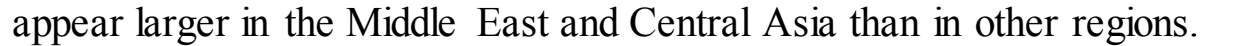

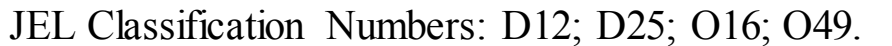

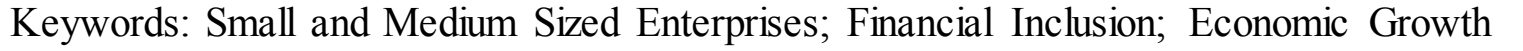

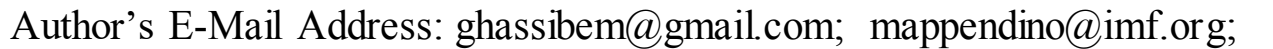

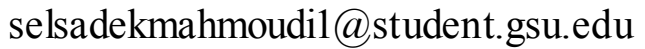

(CInternational Monetary Fund. Not for Redistribution 


\section{INTRODUCTION}

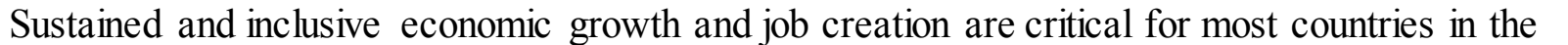

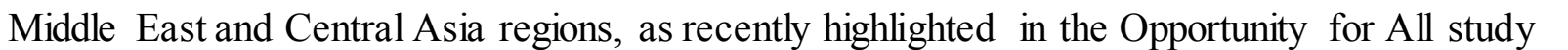

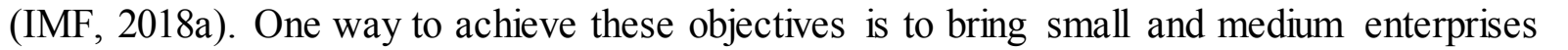

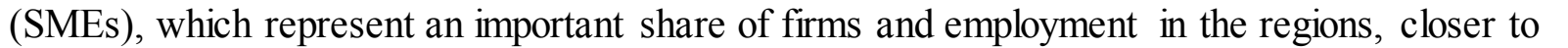

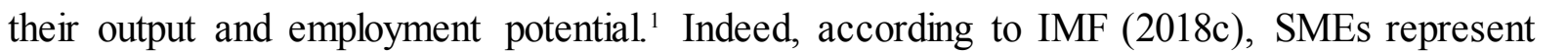

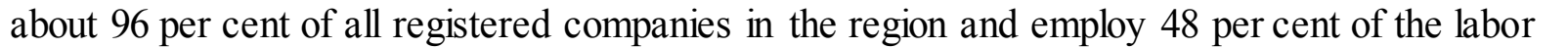

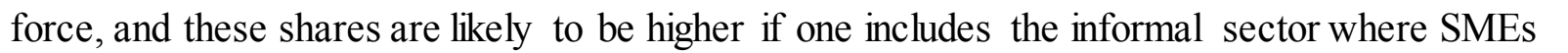

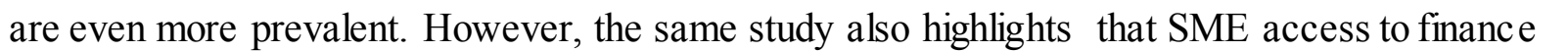

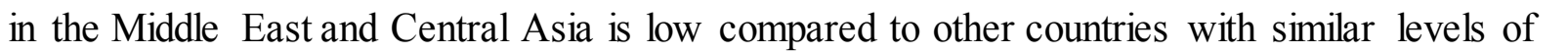

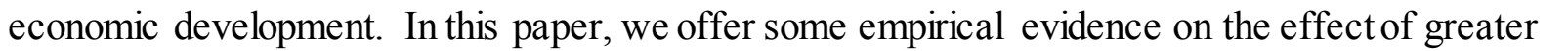

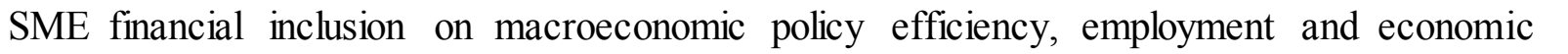

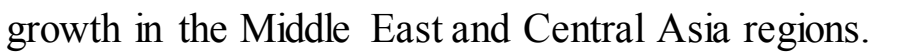

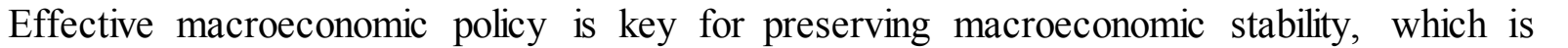

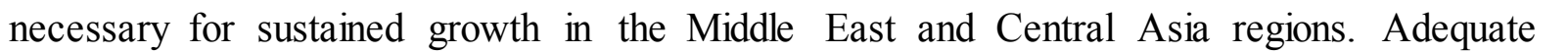

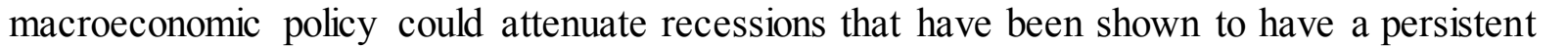

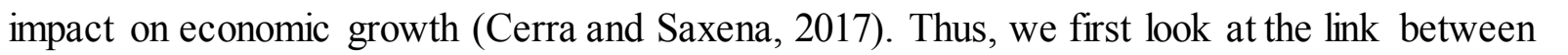

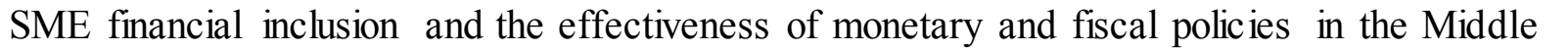

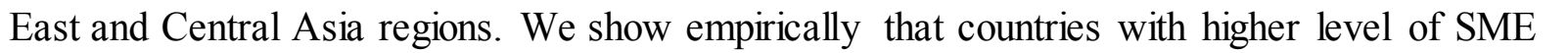

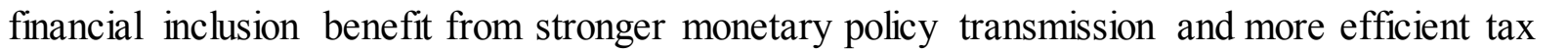

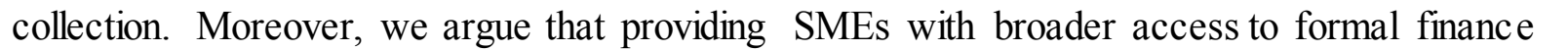

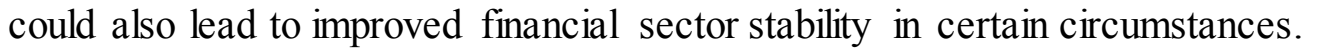

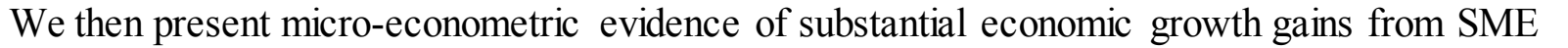

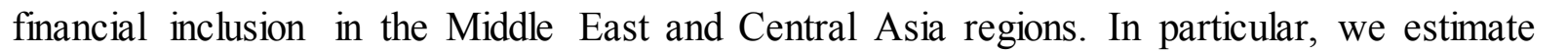

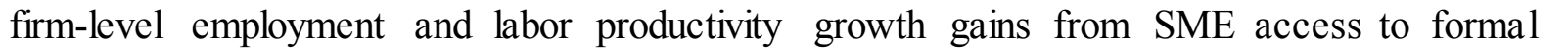

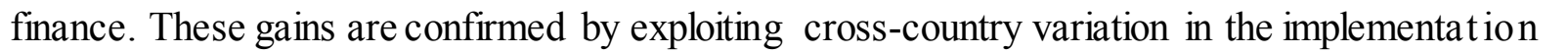

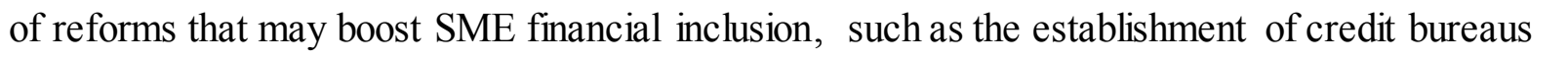

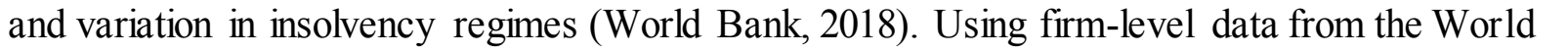

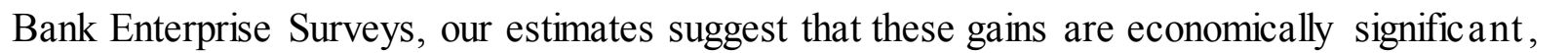

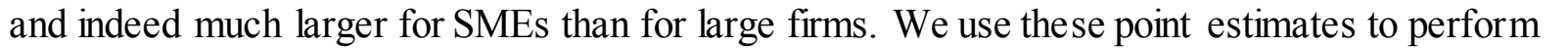

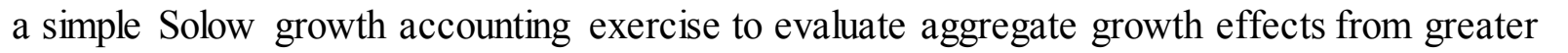

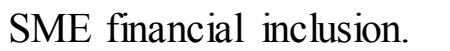

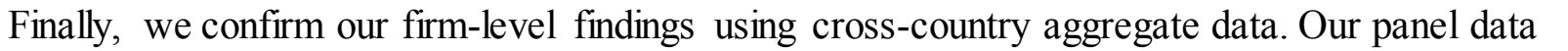

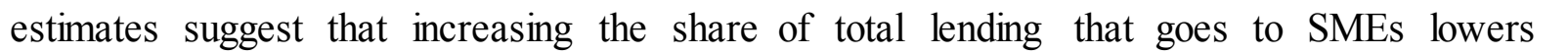

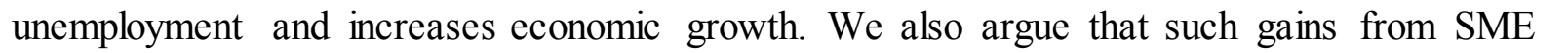

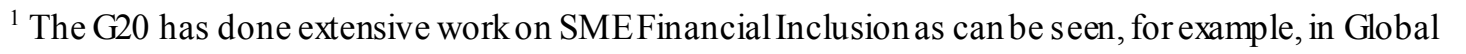

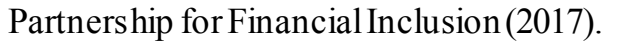




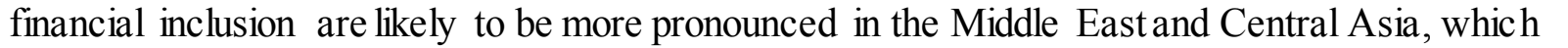

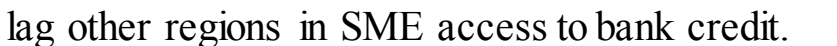

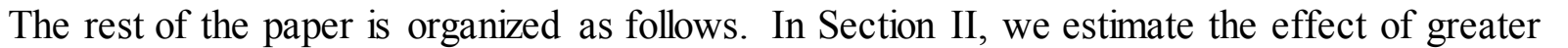

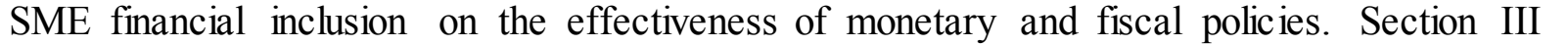

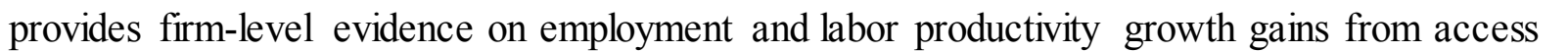

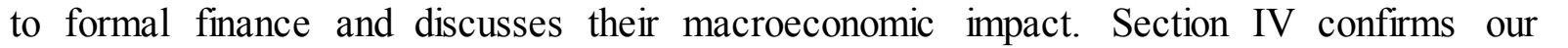

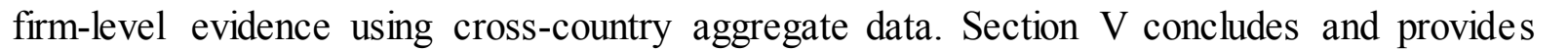

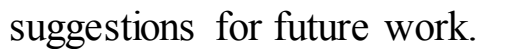

\section{Macroeconomic Policies AND SME Financial InCLUS ION}

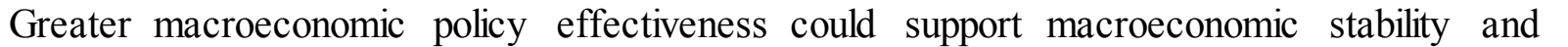

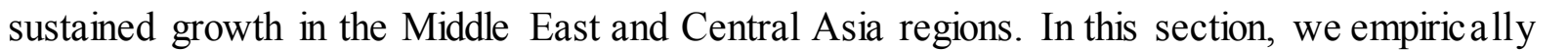

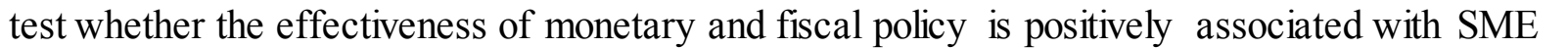

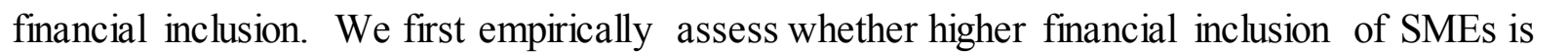

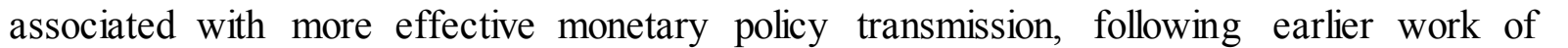

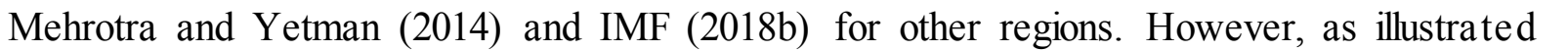

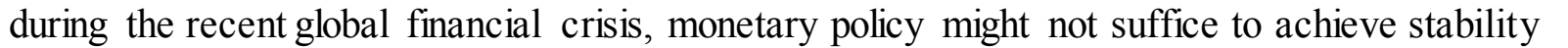

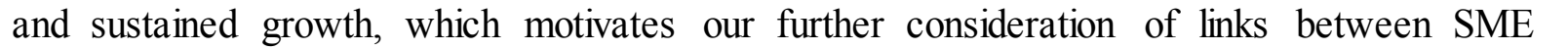

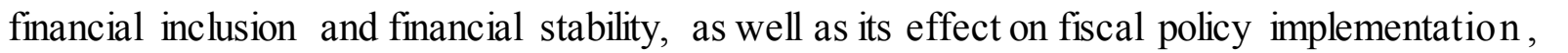

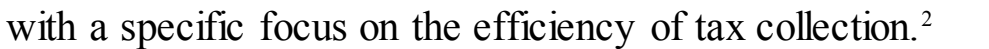

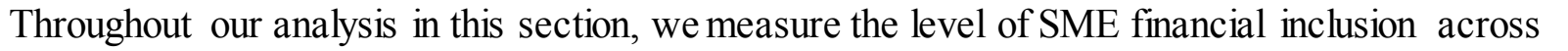

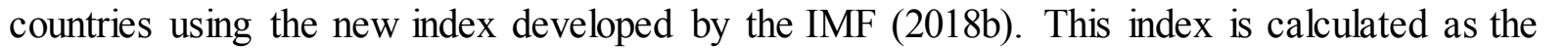

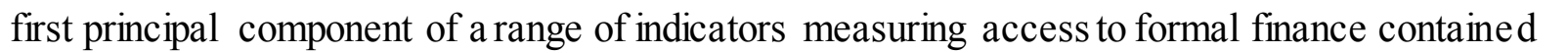

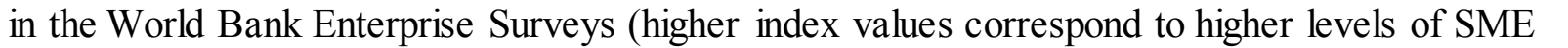

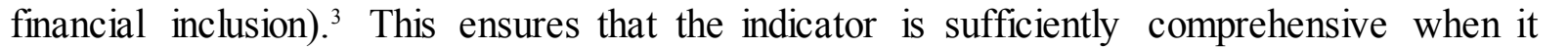

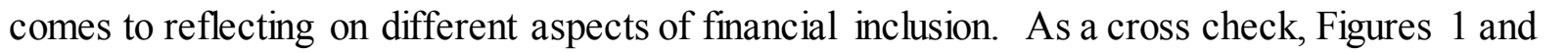

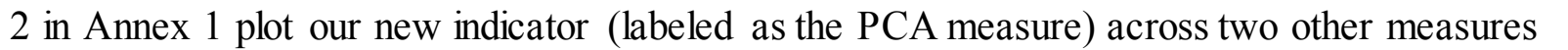

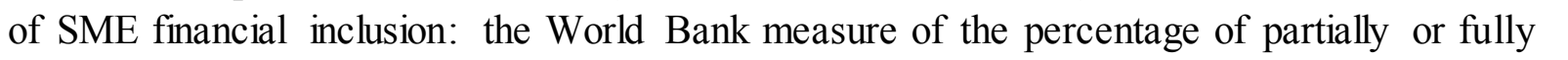

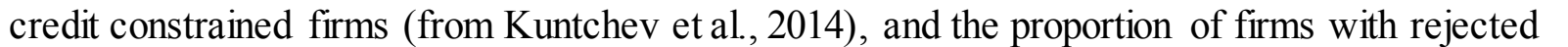

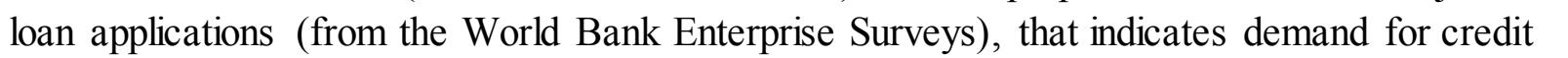

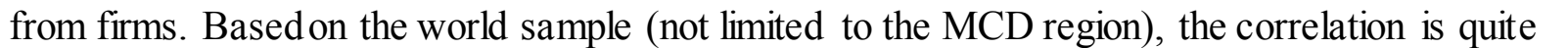

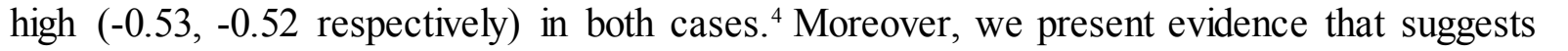
पा

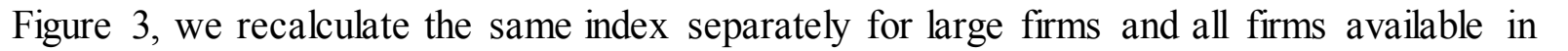

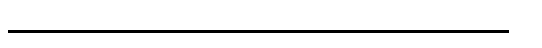

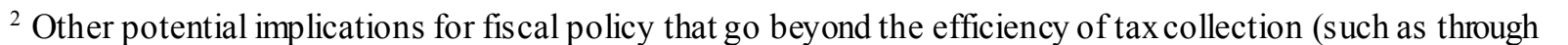

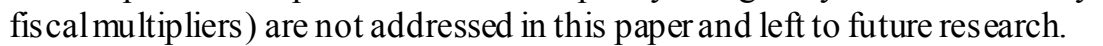

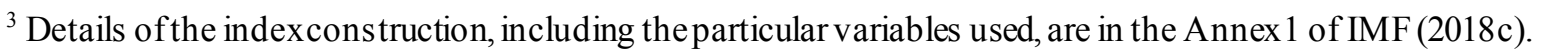

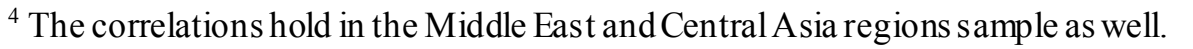

CInternational Monetary Fund. Not for Redistribution 


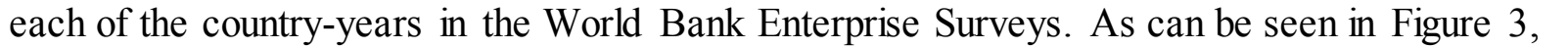

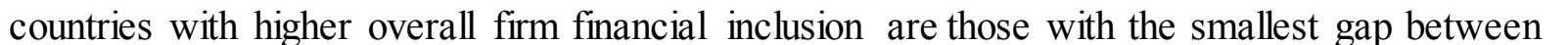

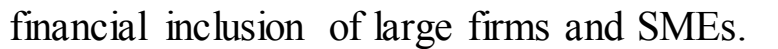

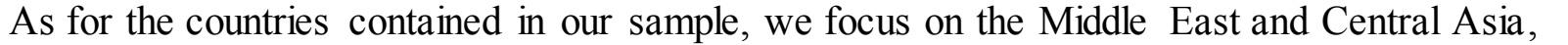

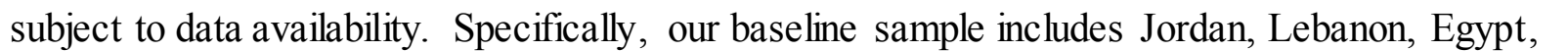

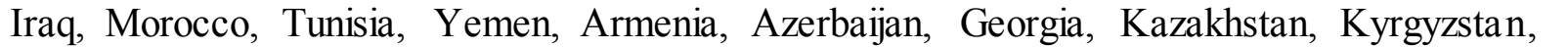

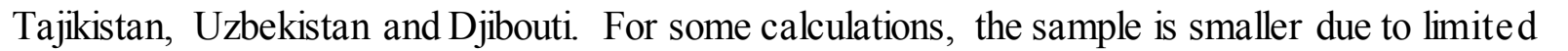

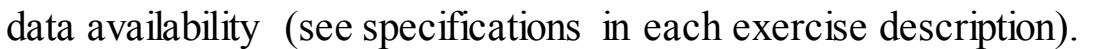

\section{A. SME Financial Inclusion and Monetary Policy Transmission}

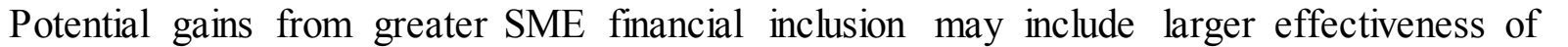

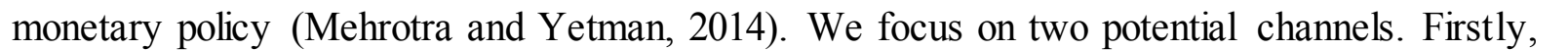

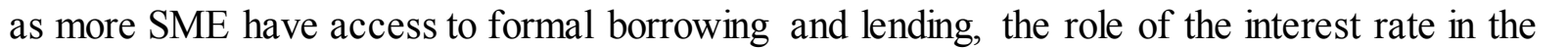

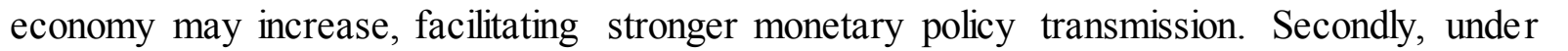

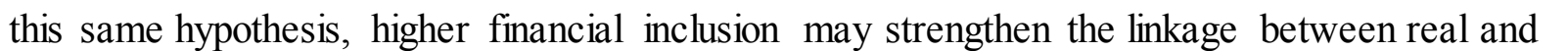

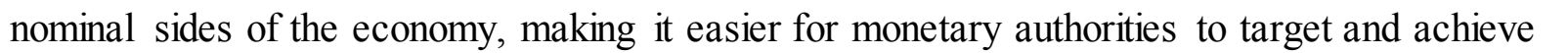

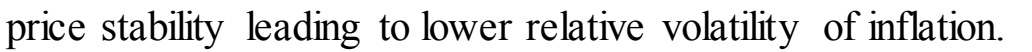

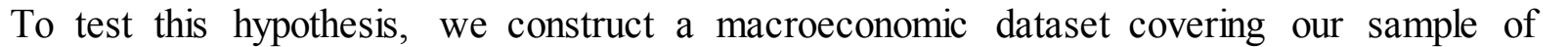

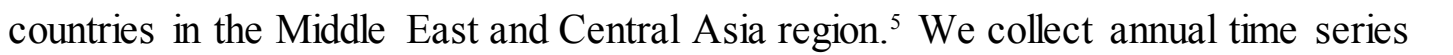

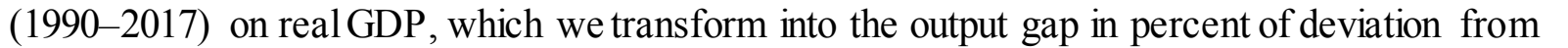

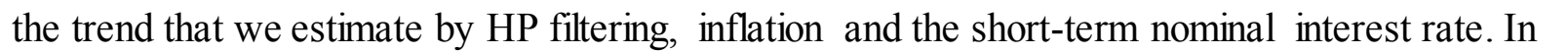

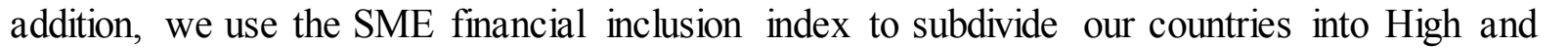

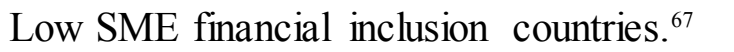

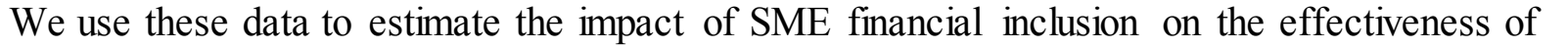

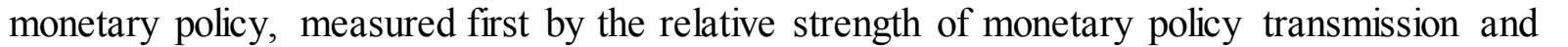

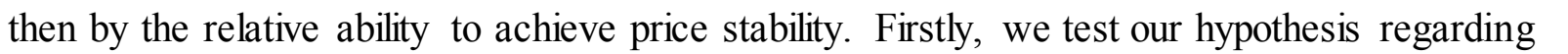

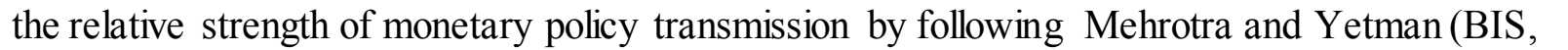

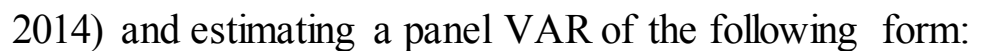

mIm

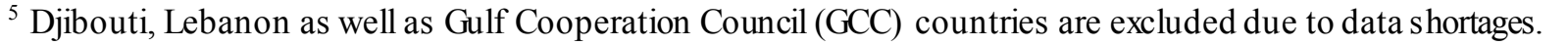

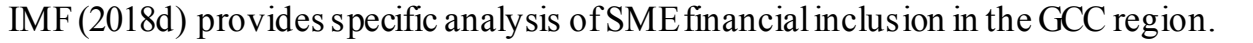

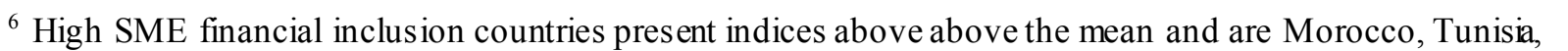

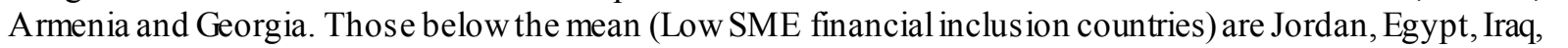

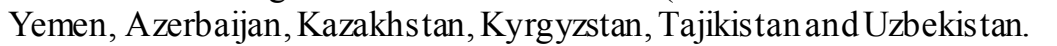

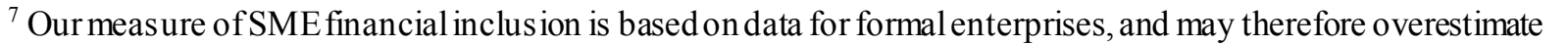

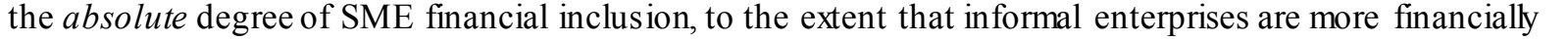

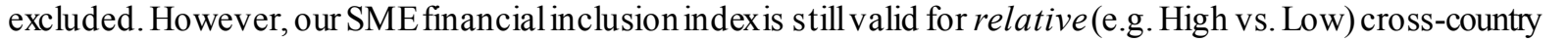

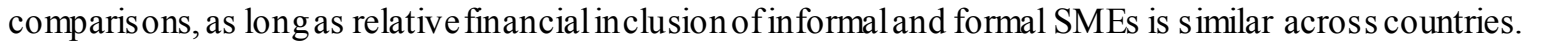




$$
Y_{i t}=A Y_{i, t-1}+u_{i}+v_{t}+e_{i t}
$$

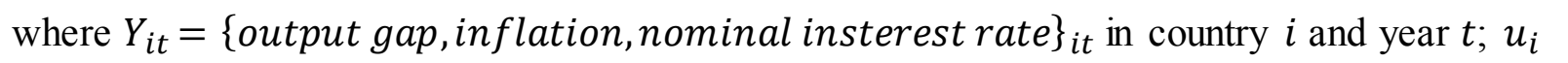

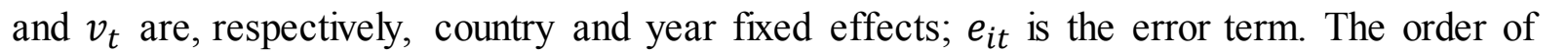

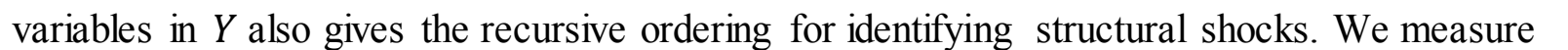

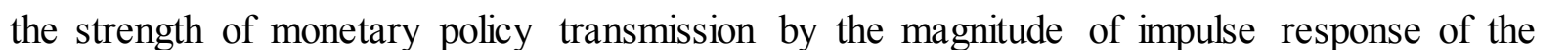

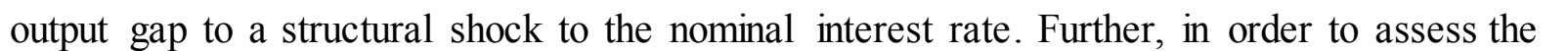

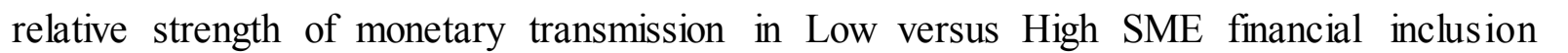

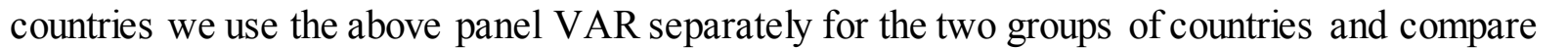

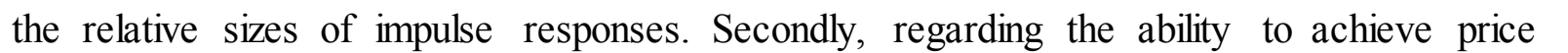

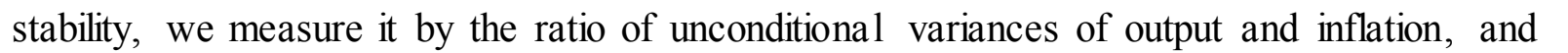

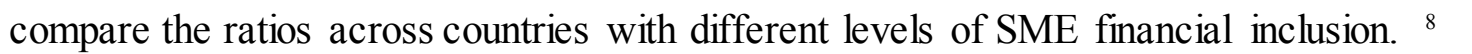

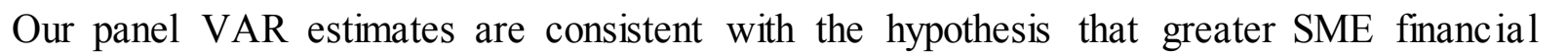

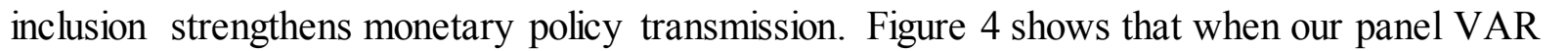

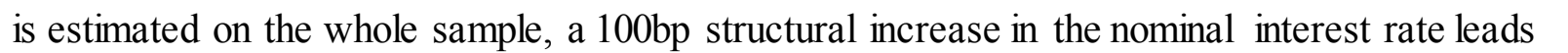

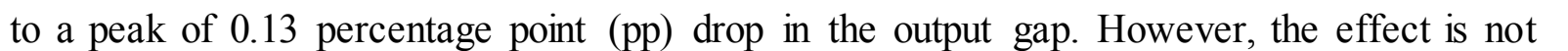

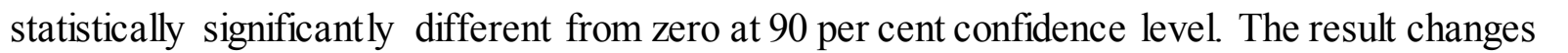

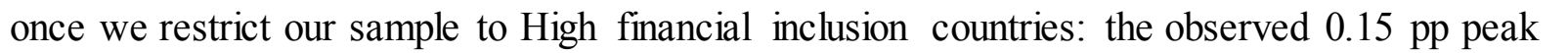

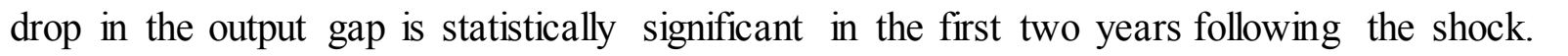

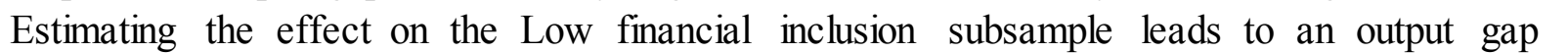

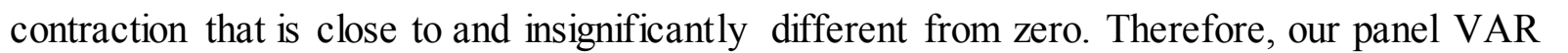

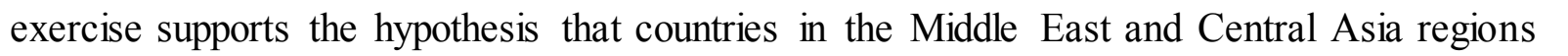

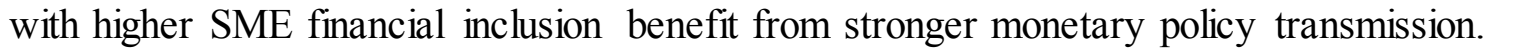

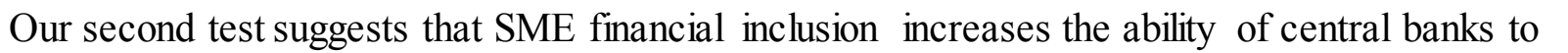

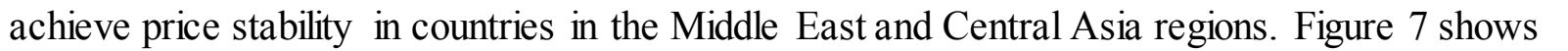

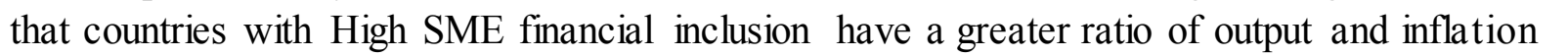

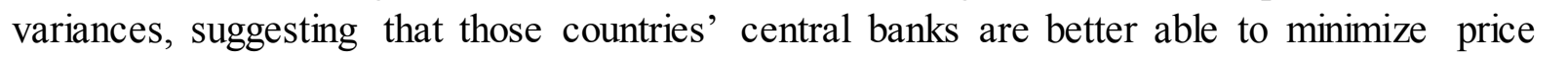

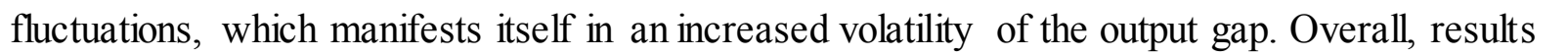

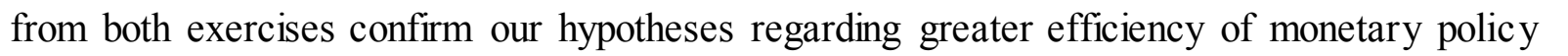

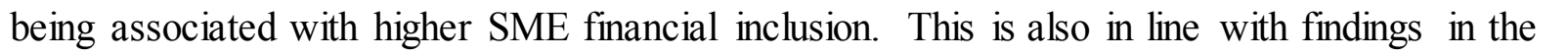

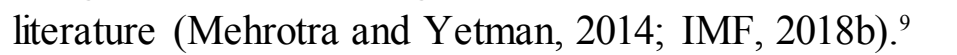

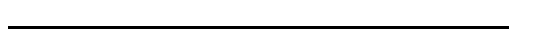

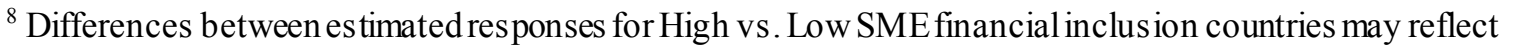

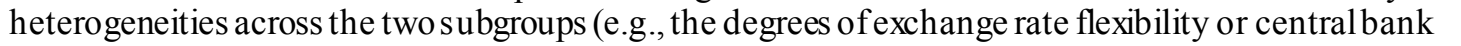

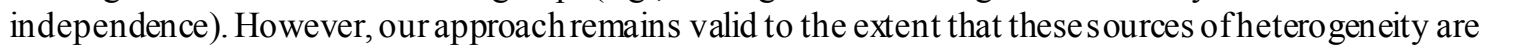

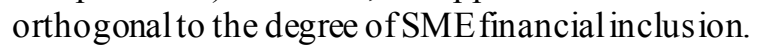

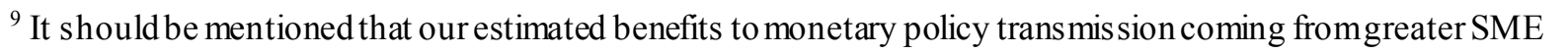

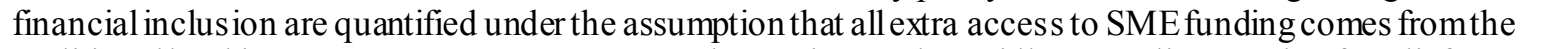

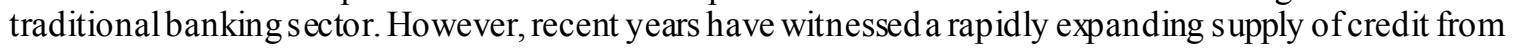

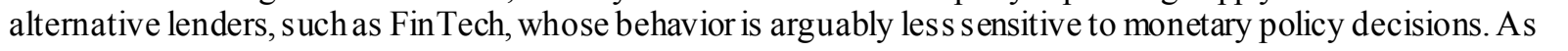
$\square$ 


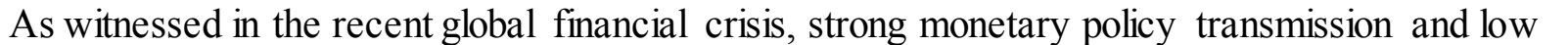

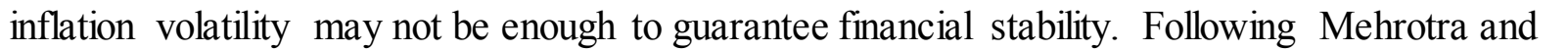

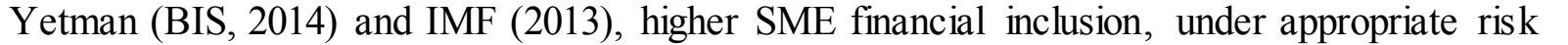

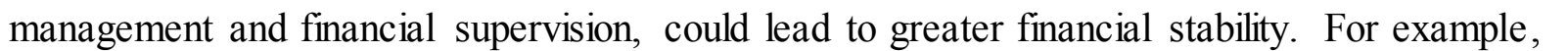

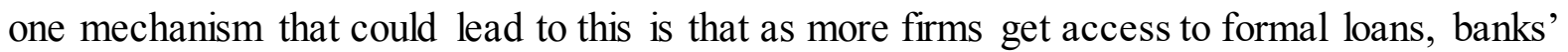

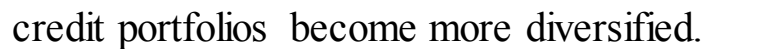

\section{B. SME Financial Inclusion and Tax Collection}

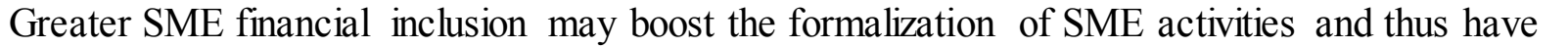

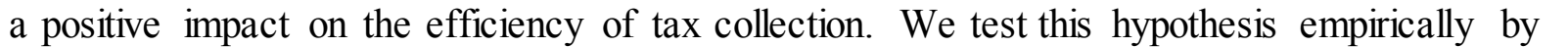

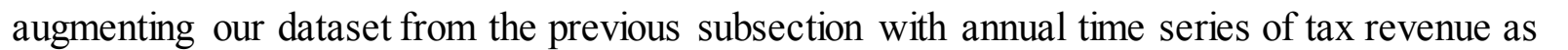

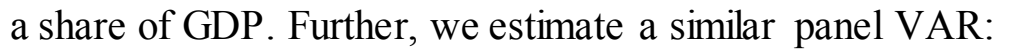

$$
Y_{i t}=A Y_{i, t-1}+u_{i}+v_{t}+e_{i t}
$$

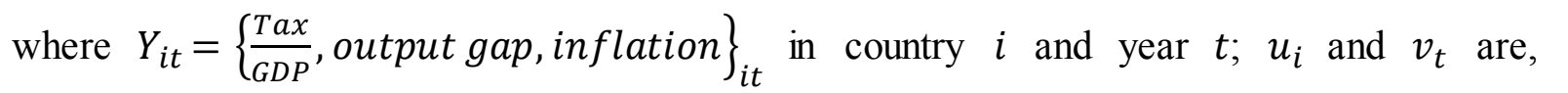

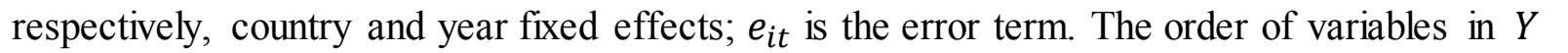

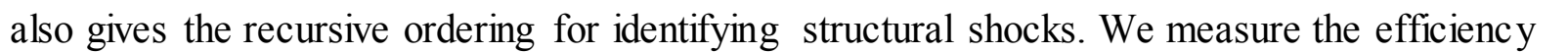

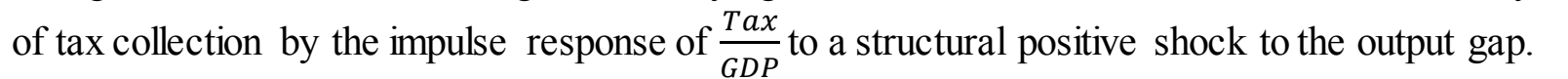

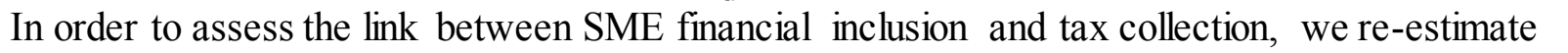

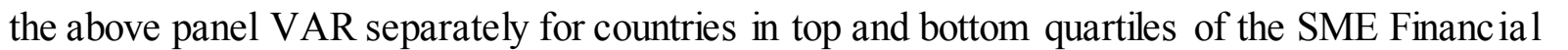

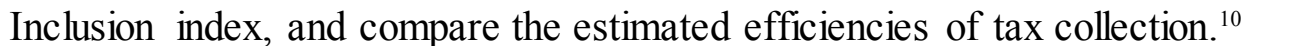

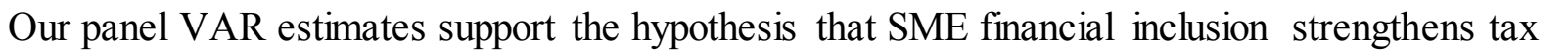

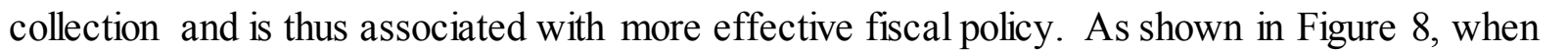

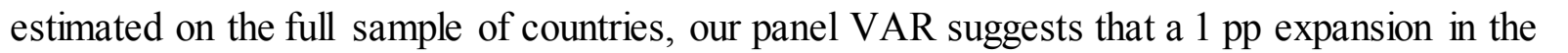

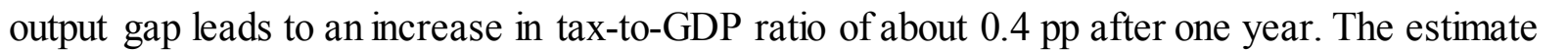

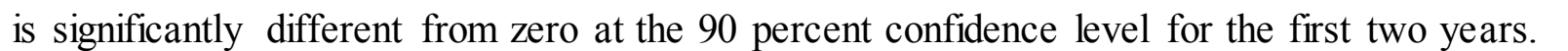

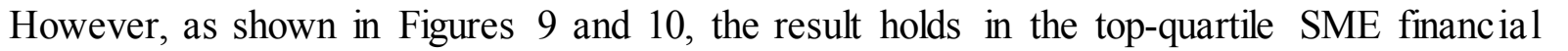

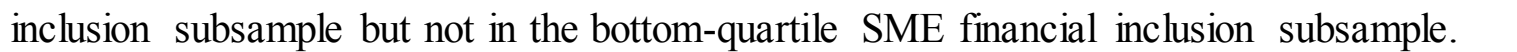

\section{EMPLOYMENT AND LABOR PRODUCTIVITy GAINS FROM SME FinANCIAL INCLUS ION}

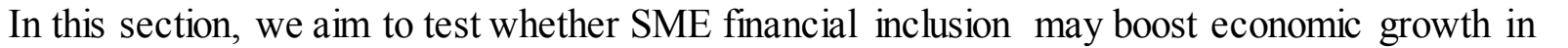

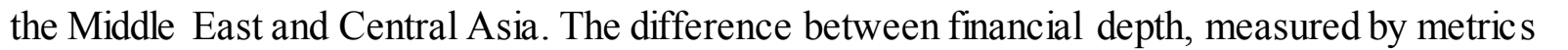

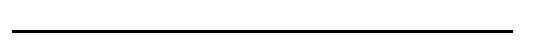

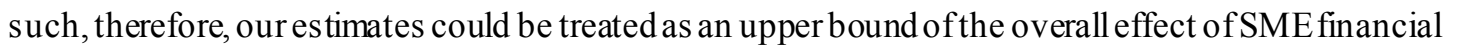

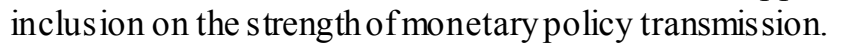

प

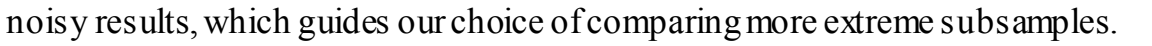

(CInternational Monetary Fund. Not for Redistribution 


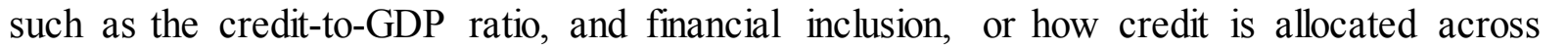

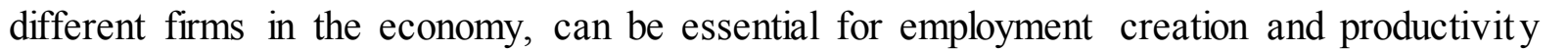

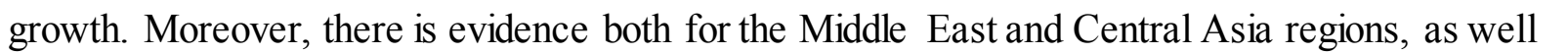

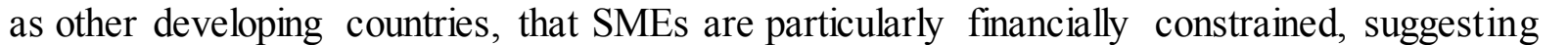

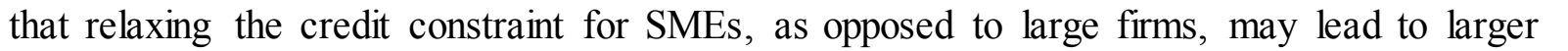

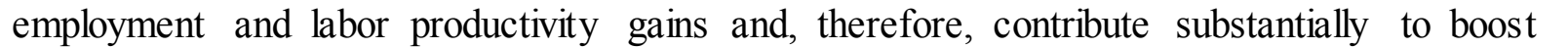

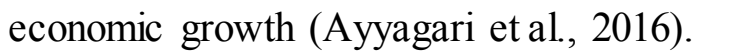

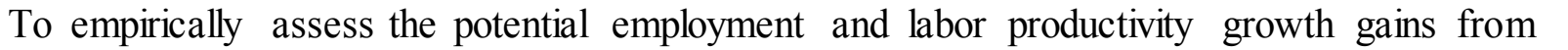

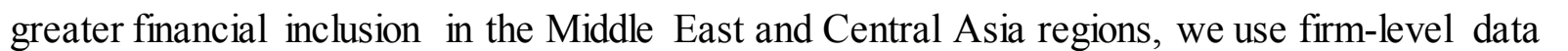

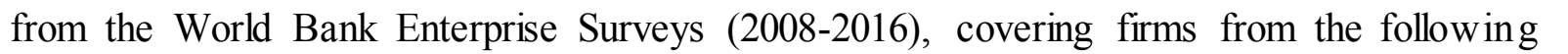

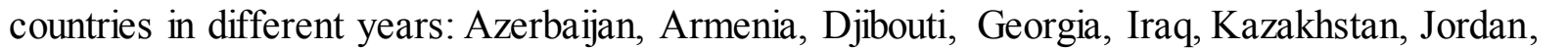

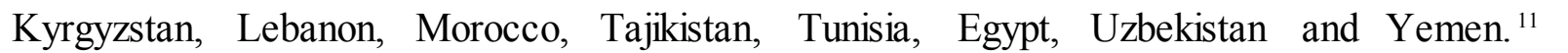

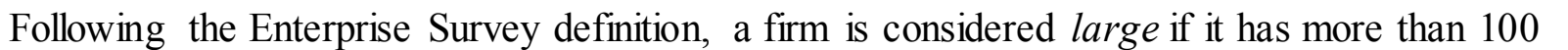

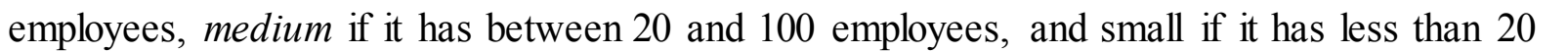
$\square \square[11 \mathbb{\square} \square$

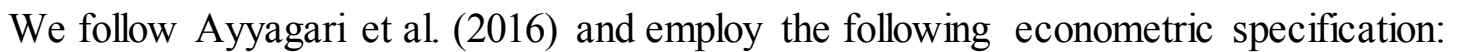

$$
\Delta E_{i j t}=\alpha F_{i j t}+\beta X_{i j t}+Z_{j t}+C_{j}+Y_{t}+\varepsilon_{i j t}
$$

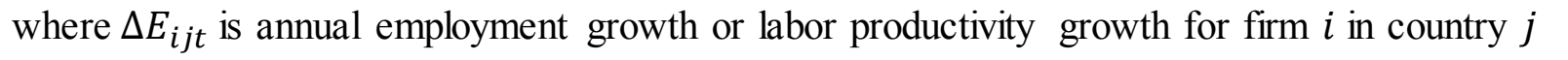

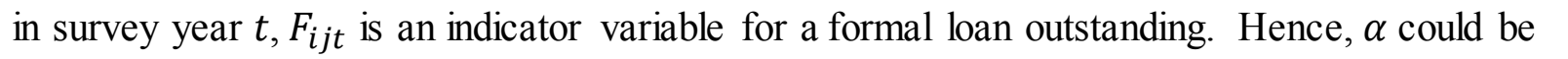

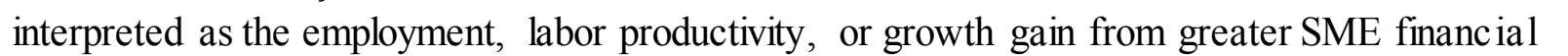

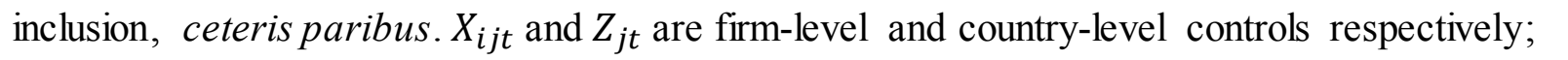

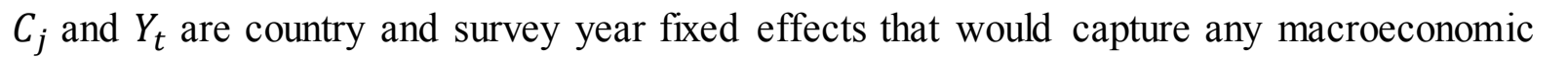

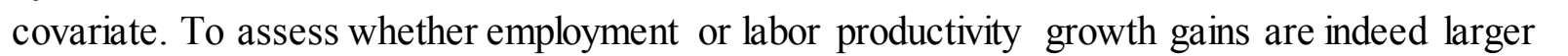

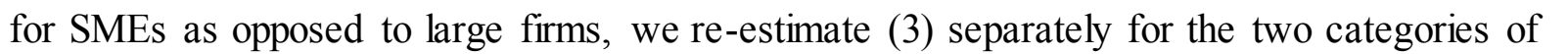

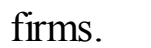

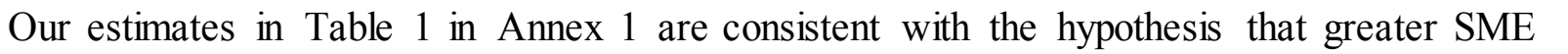

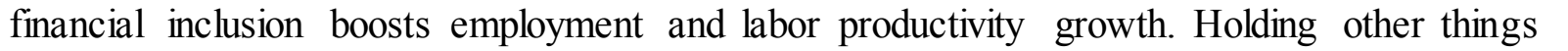

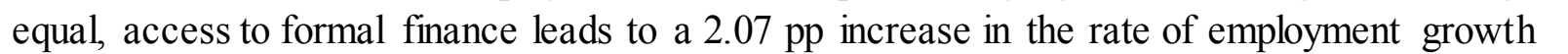

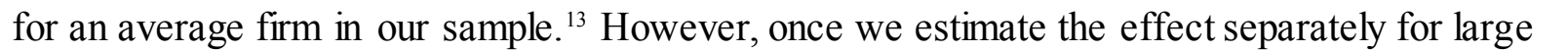

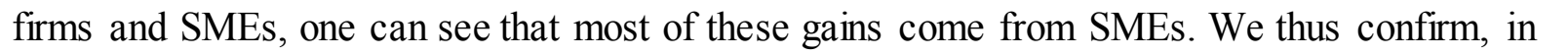

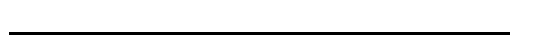

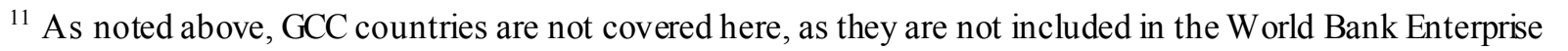

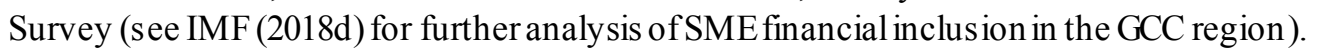

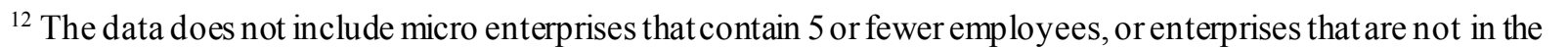

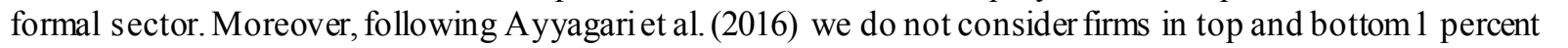

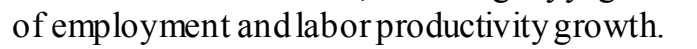

प

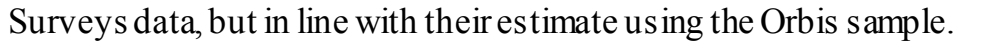




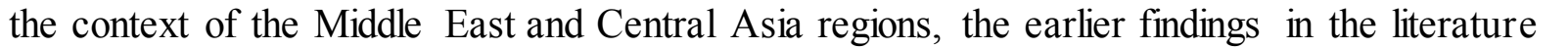

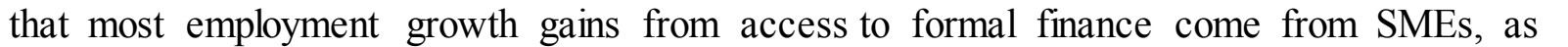

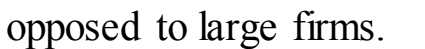

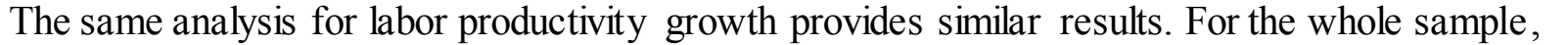

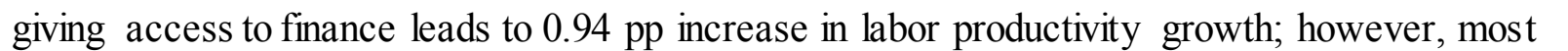

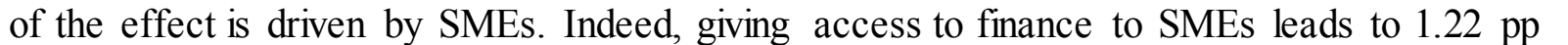

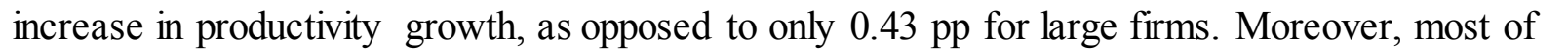

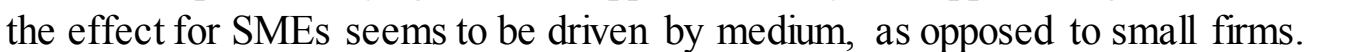

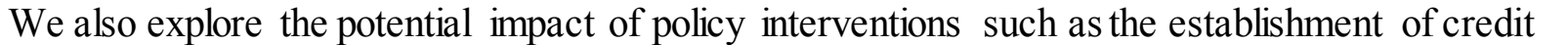

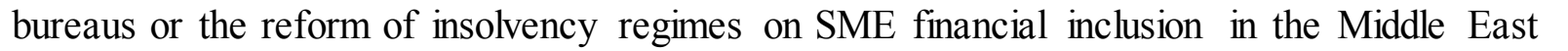

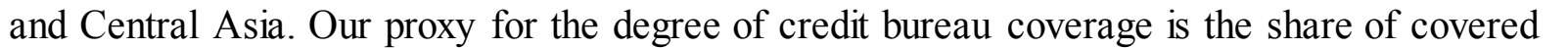

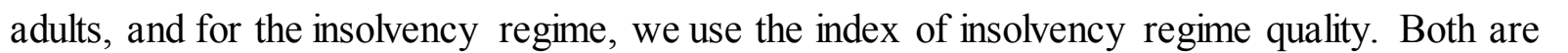

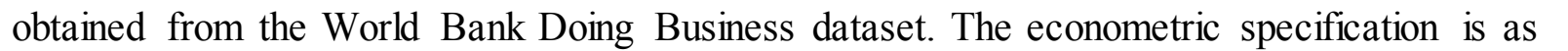

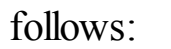

$$
\Delta E_{i j t}=\alpha S_{j t}+\beta X_{i j t}+Z_{j t}+C_{j}+Y_{t}+\varepsilon_{i j t}
$$

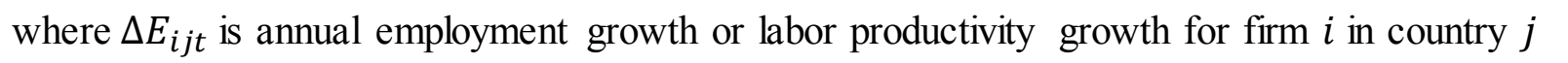

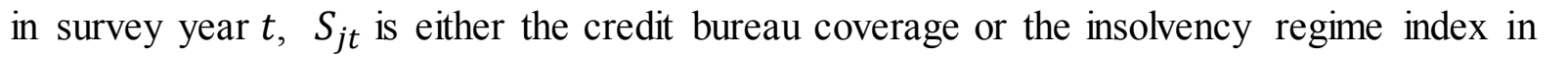

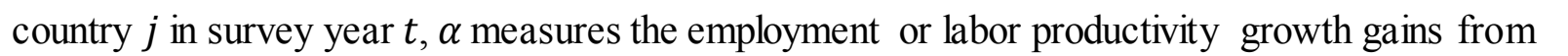

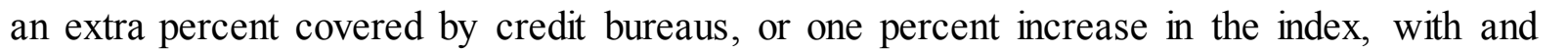

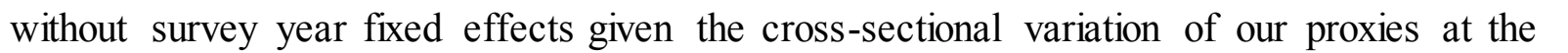

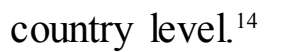

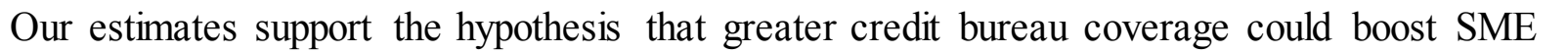

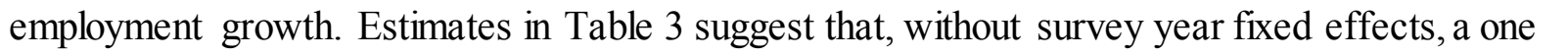

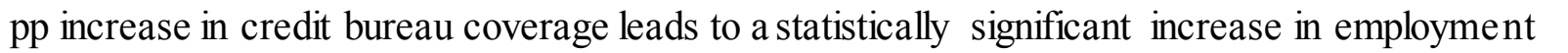

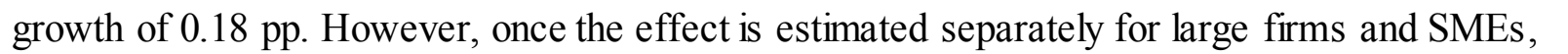
the effect on large firms' employment growth is small and insignificant from zero, whereas

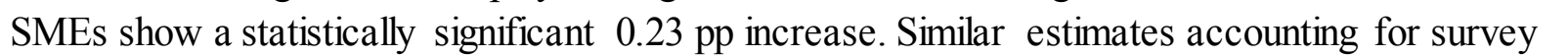

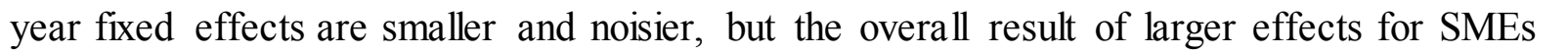

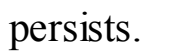

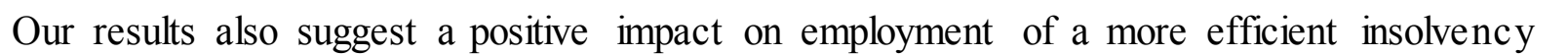

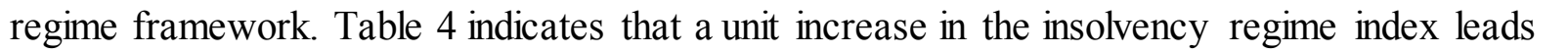

mm+m

प

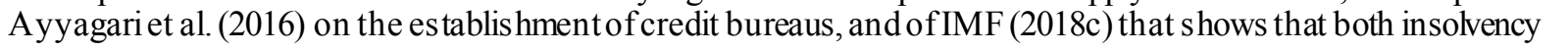

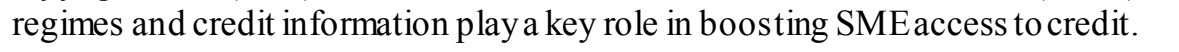




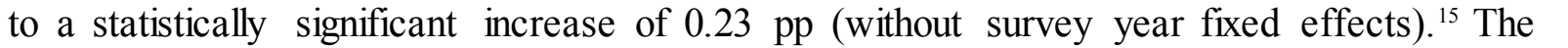

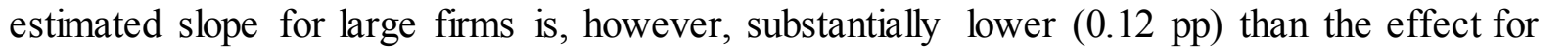

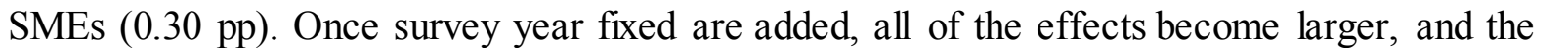

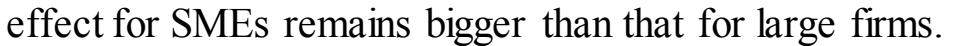

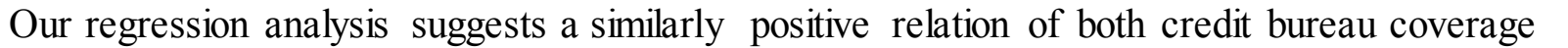

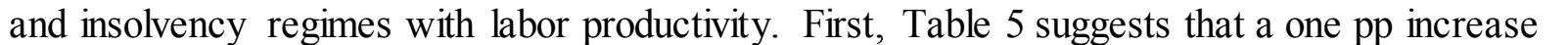

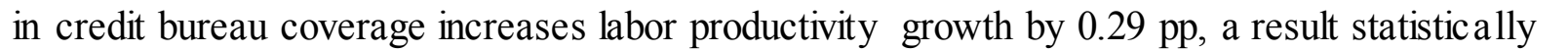

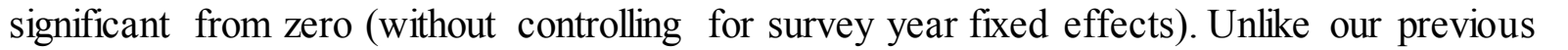

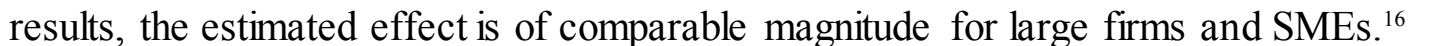

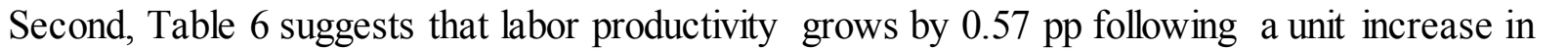

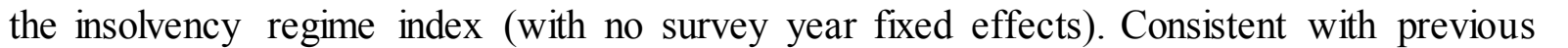

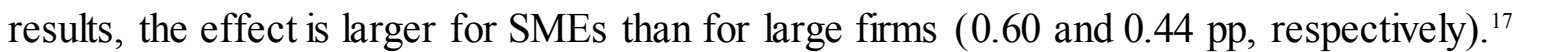

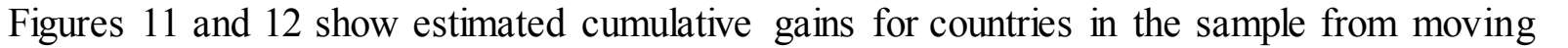

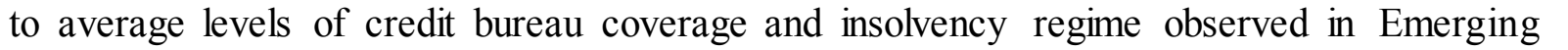

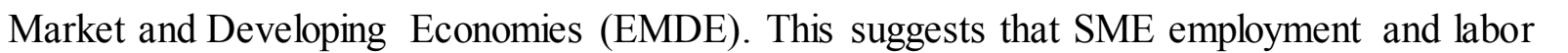

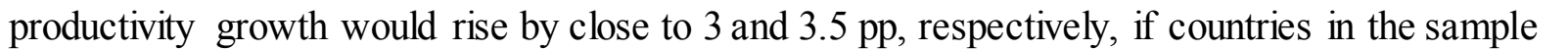

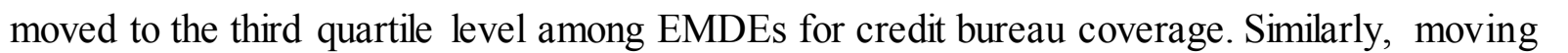

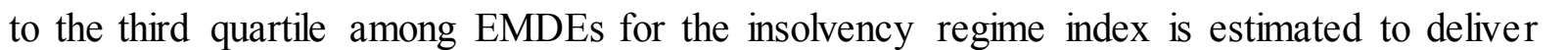

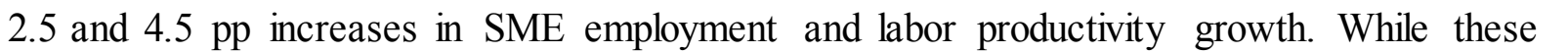

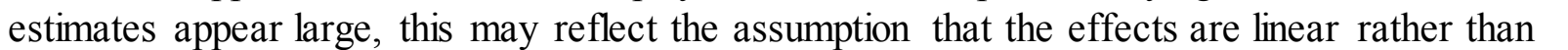

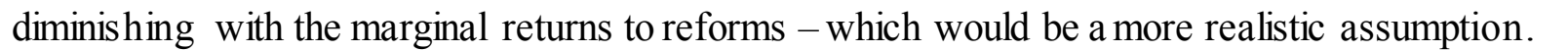

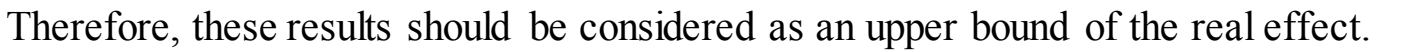

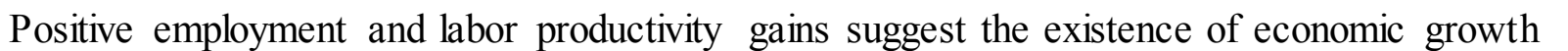

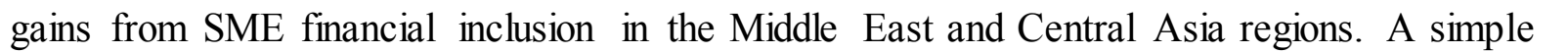

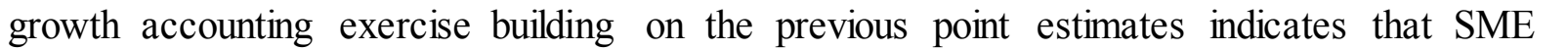
ए

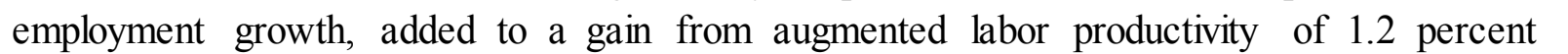

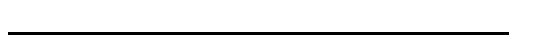

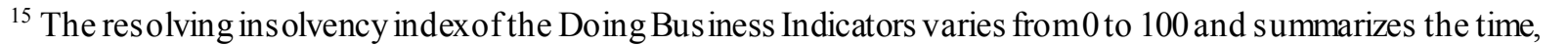

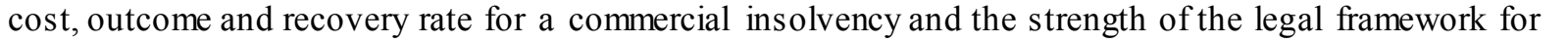

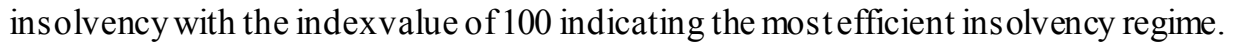

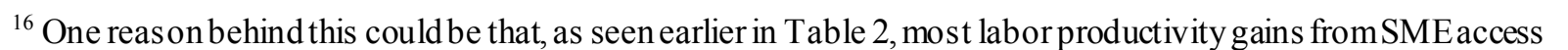
प

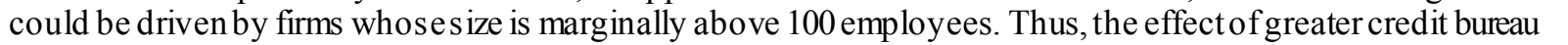

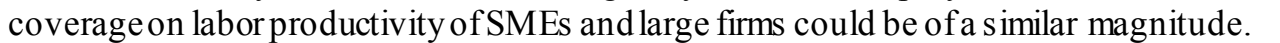

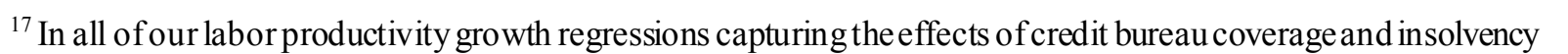

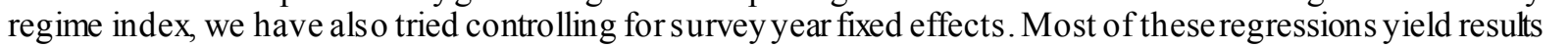

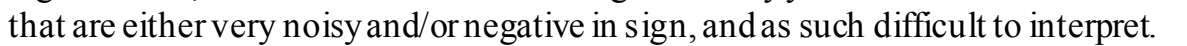




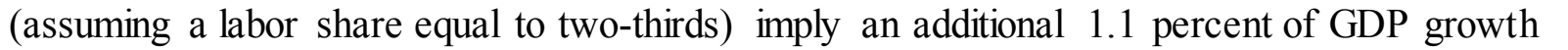

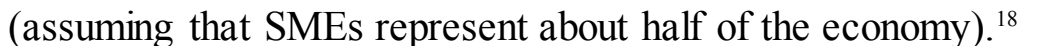

\section{Middle Eas t and Central As ia in a Cross-Country Pers pective}

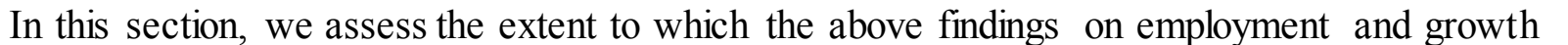

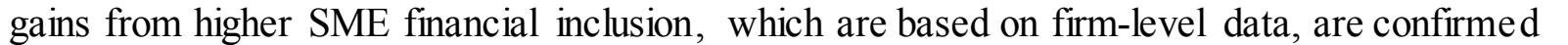

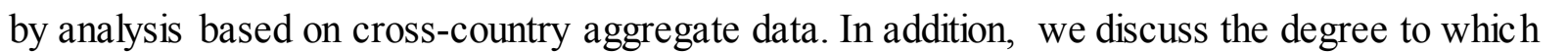

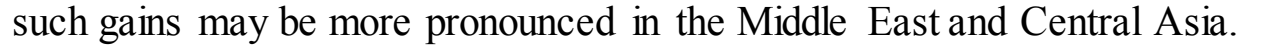

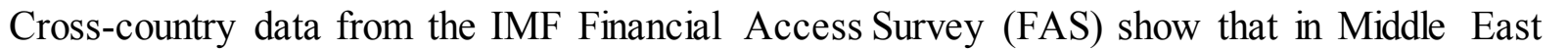

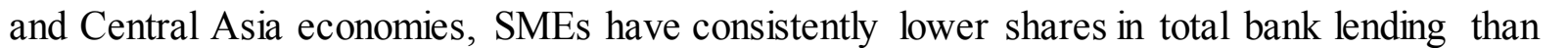

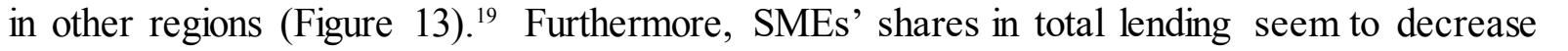

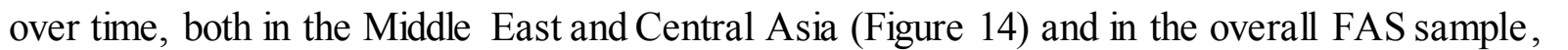

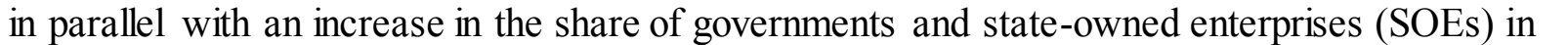

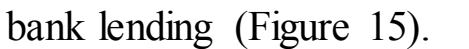

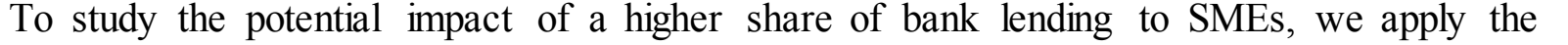

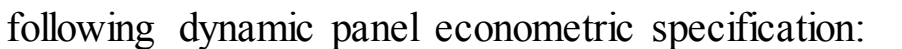

$$
\begin{aligned}
\mathrm{U}_{i t}=\delta \mathrm{U}_{i t-1} & +\beta_{1} \text { SME_Share }_{i t}+\beta_{2} F D_{i t}+\beta_{3} \text { SME_Share }_{i t} \times F D_{i t}+\theta X_{i t}+\gamma_{t}+\alpha_{i} \\
& +\varepsilon_{i t} \quad(5)
\end{aligned}
$$

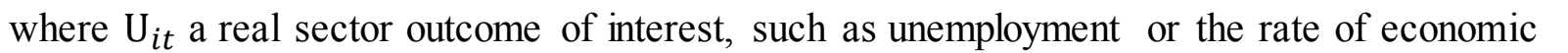

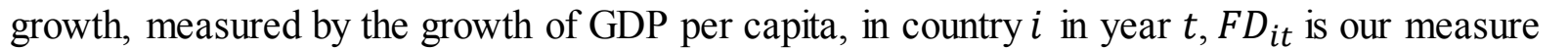

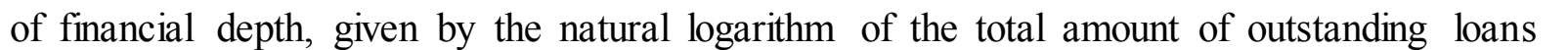

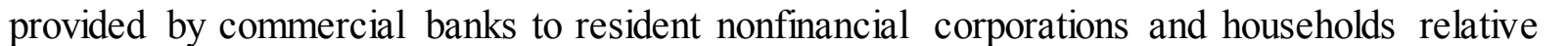

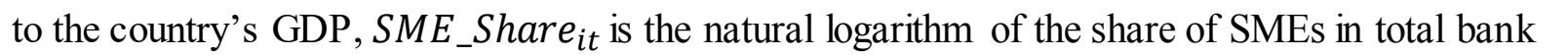

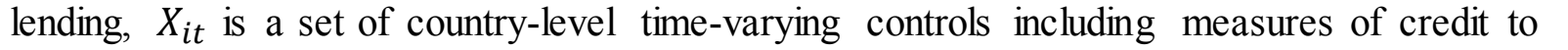

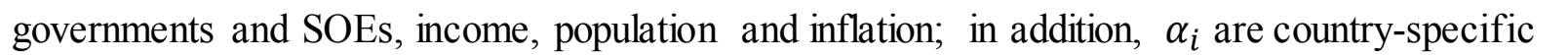

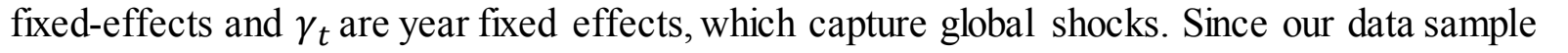

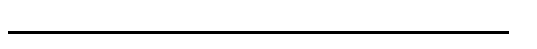

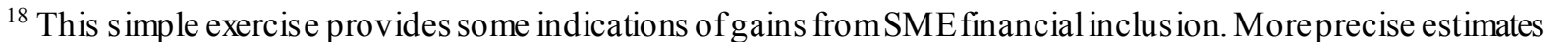

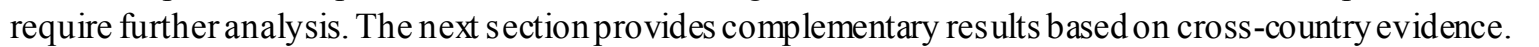

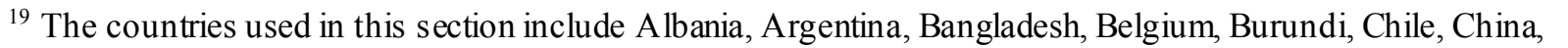

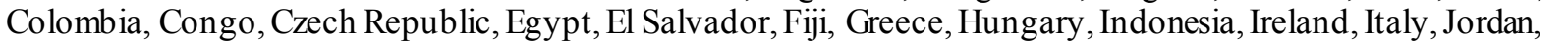

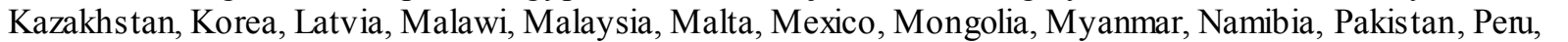

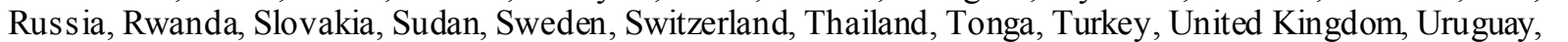

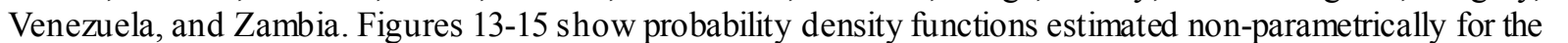

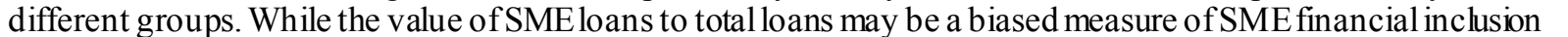
(1)

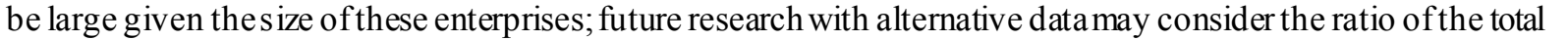

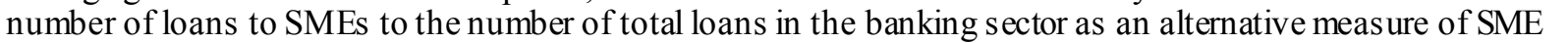

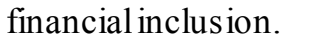




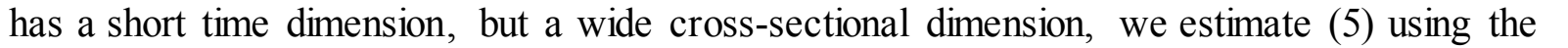

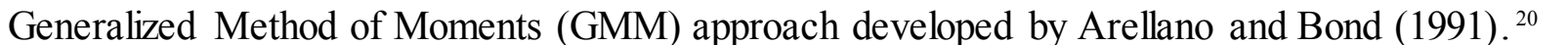

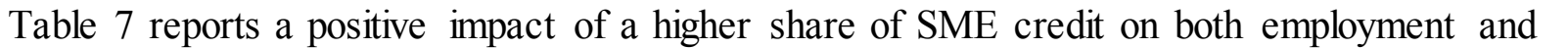

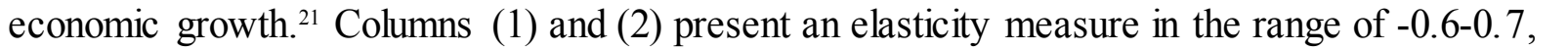

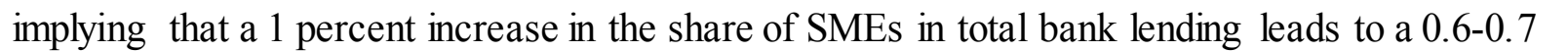

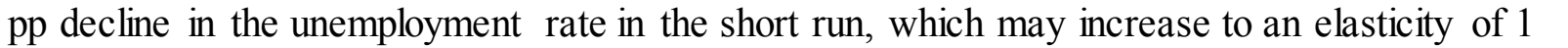

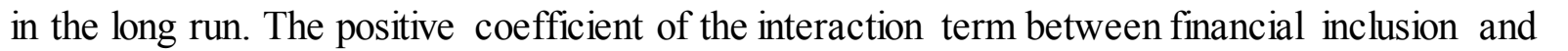

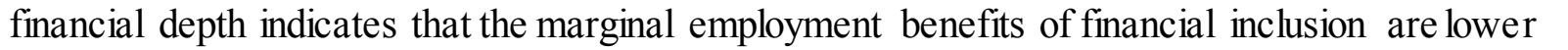

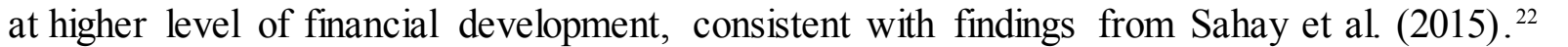

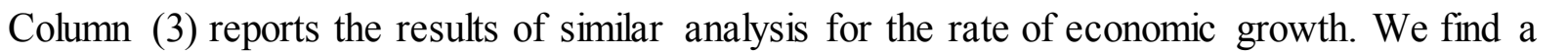

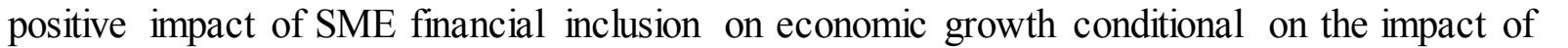

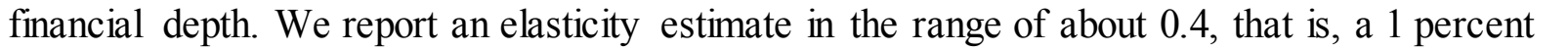

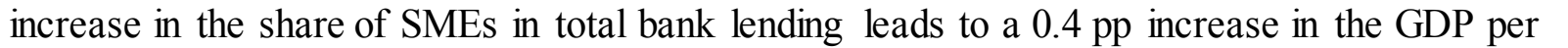

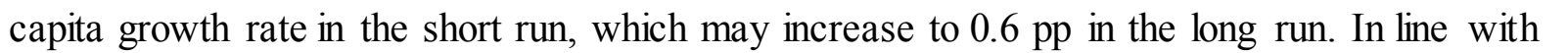

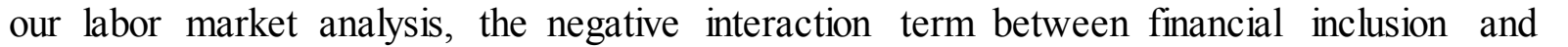

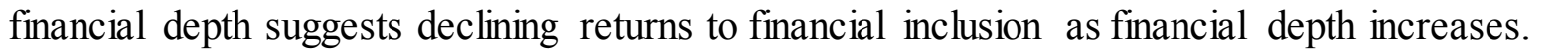

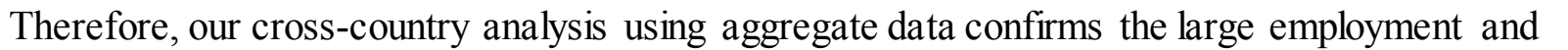

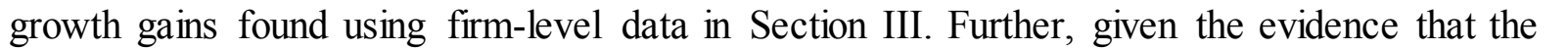

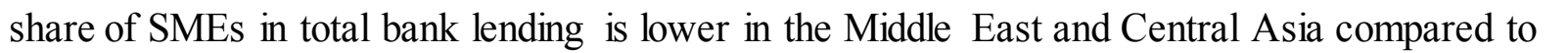

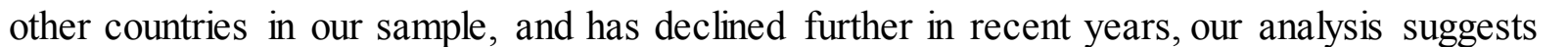

(1)

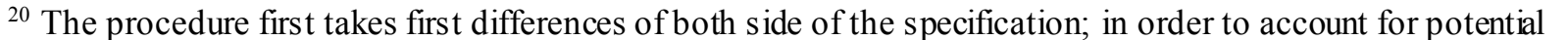

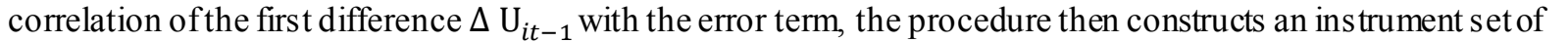

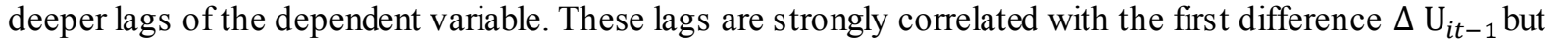

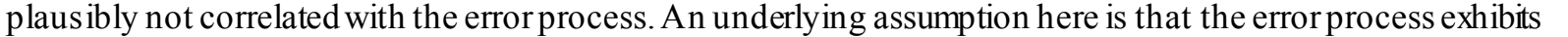

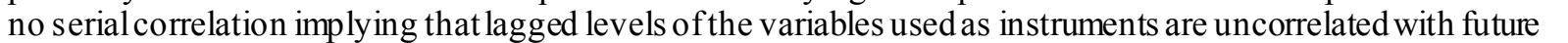

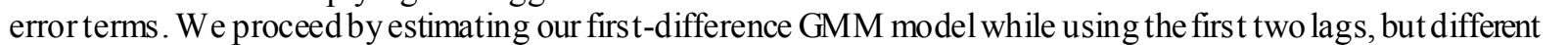

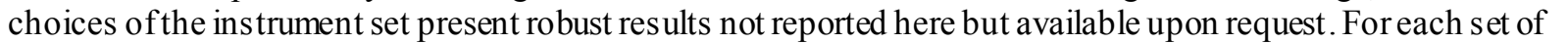

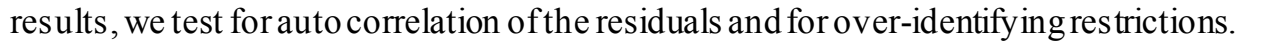

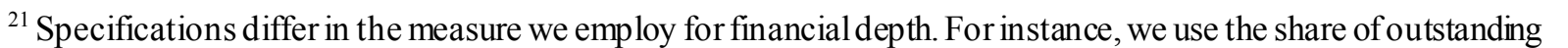

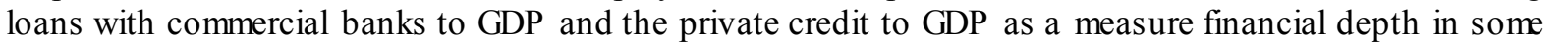

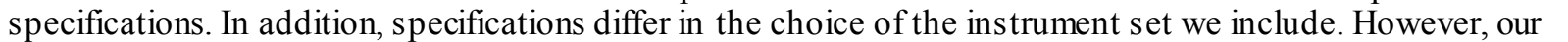

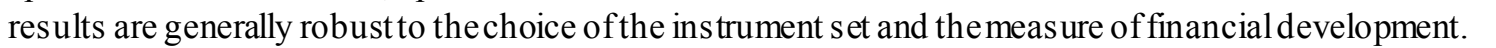

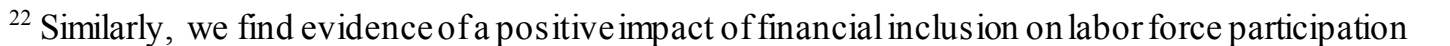

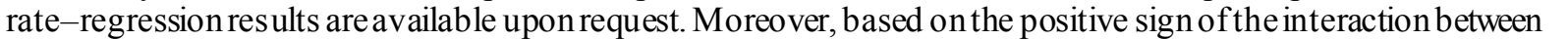

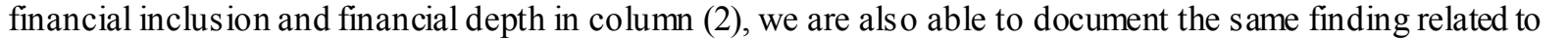

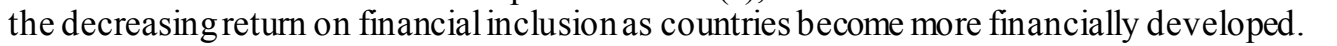
$\square$

$\square$
}

CInternational Monetary Fund. Not for Redistribution 


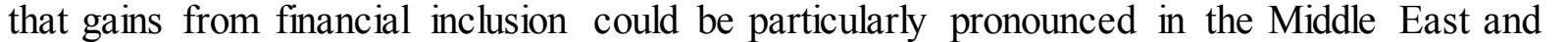

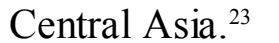

\section{CONCLUSION}

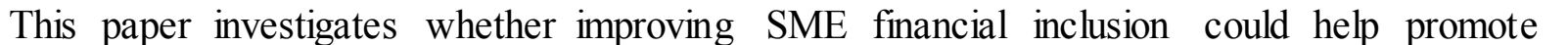

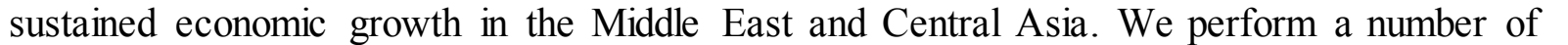

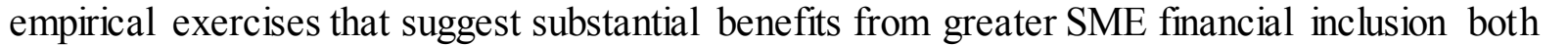

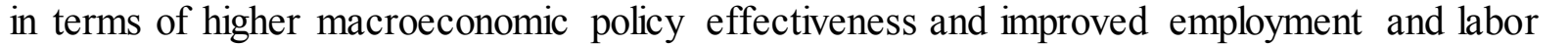

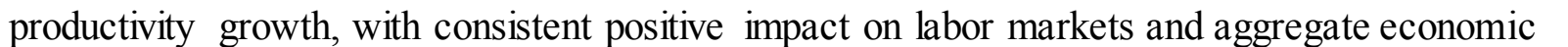
$\square \| \square \square \square$

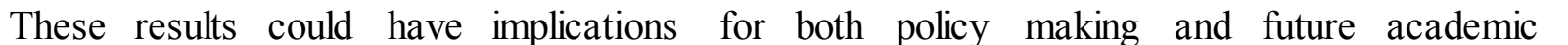

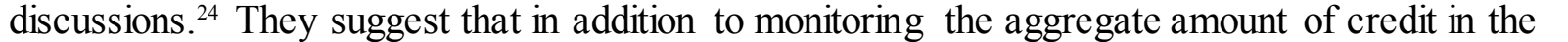

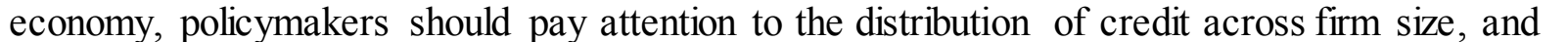

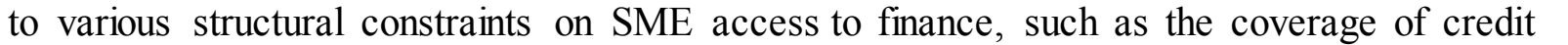

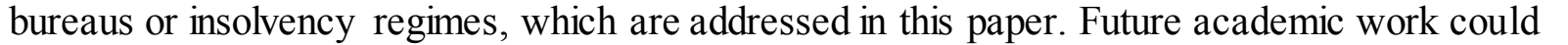

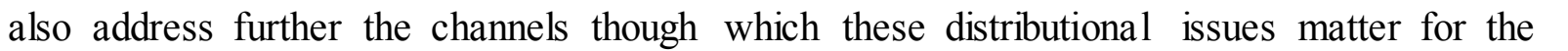

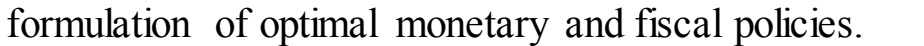

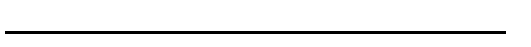

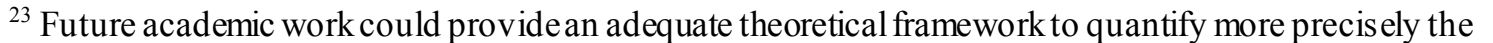

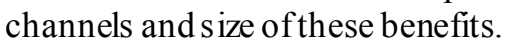

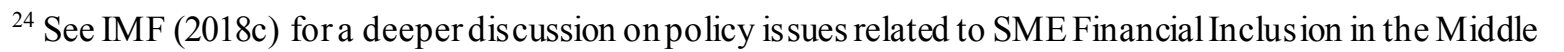

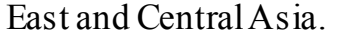




\section{REFERENCES}

Arellano, M. and S. Bond (1991). "Some tests of specification for panel data: Monte Carlo evidence and an application to employment equations",

$\square \mid \mathrm{III}$

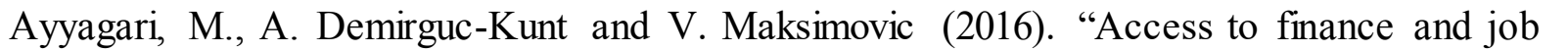

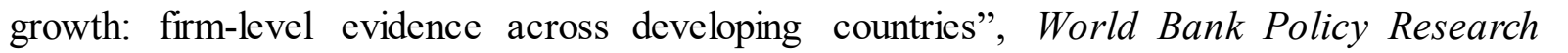

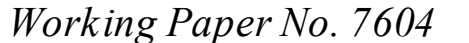

Cerra, V. and S.C. Saxena (2017). "Booms, crises and recoveries: a new paradigm of the

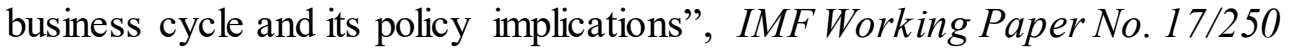

Global Partnership for Financial Inclusion (2017), "G20 Financial Inclusion Action Plan (FIAP) 2017”, Global Partnership for Financial Inclusion.

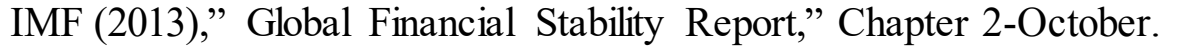

IMF (2018a), 'O and North Africa', July 2018, Departmental Paper No. 18/11

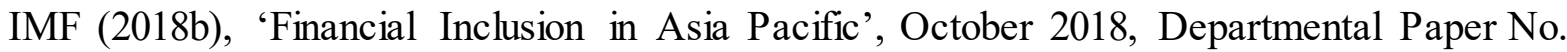
एाणा

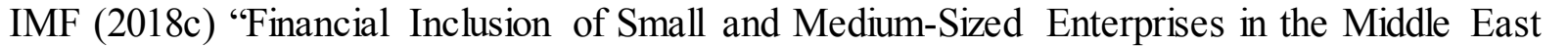

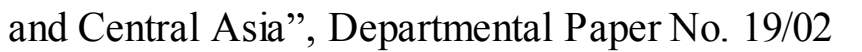

IMF (2018d) "Gulf Cooperation Council: How Developed and Inclusive are Financial Systems in the GCC?", IMF Policy Paper,

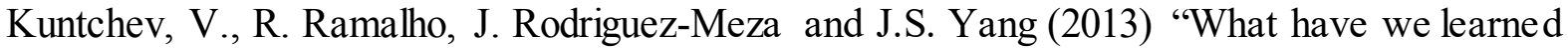

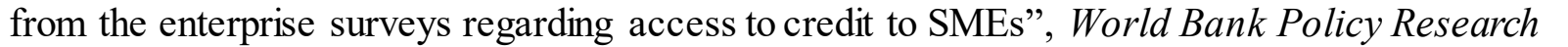

Mehrotra, A. and J. Yetman (2014). "Financial inclusion and optimal monetary policy",

Sahay, R.; Čihák, M.; N'Diaye, P.; Barajas, A.; Mitra, S.; Kyobe, A.; Mooi, Y. and $\square \square \square \square \square \square$

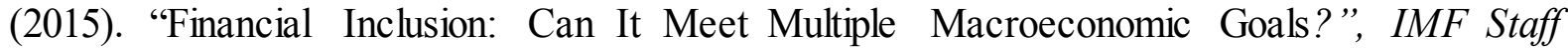

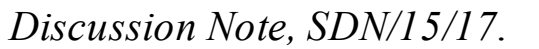

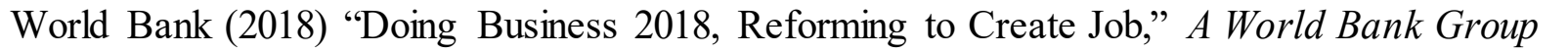

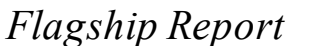


ANNEX 1. Figures ANd TABLeS

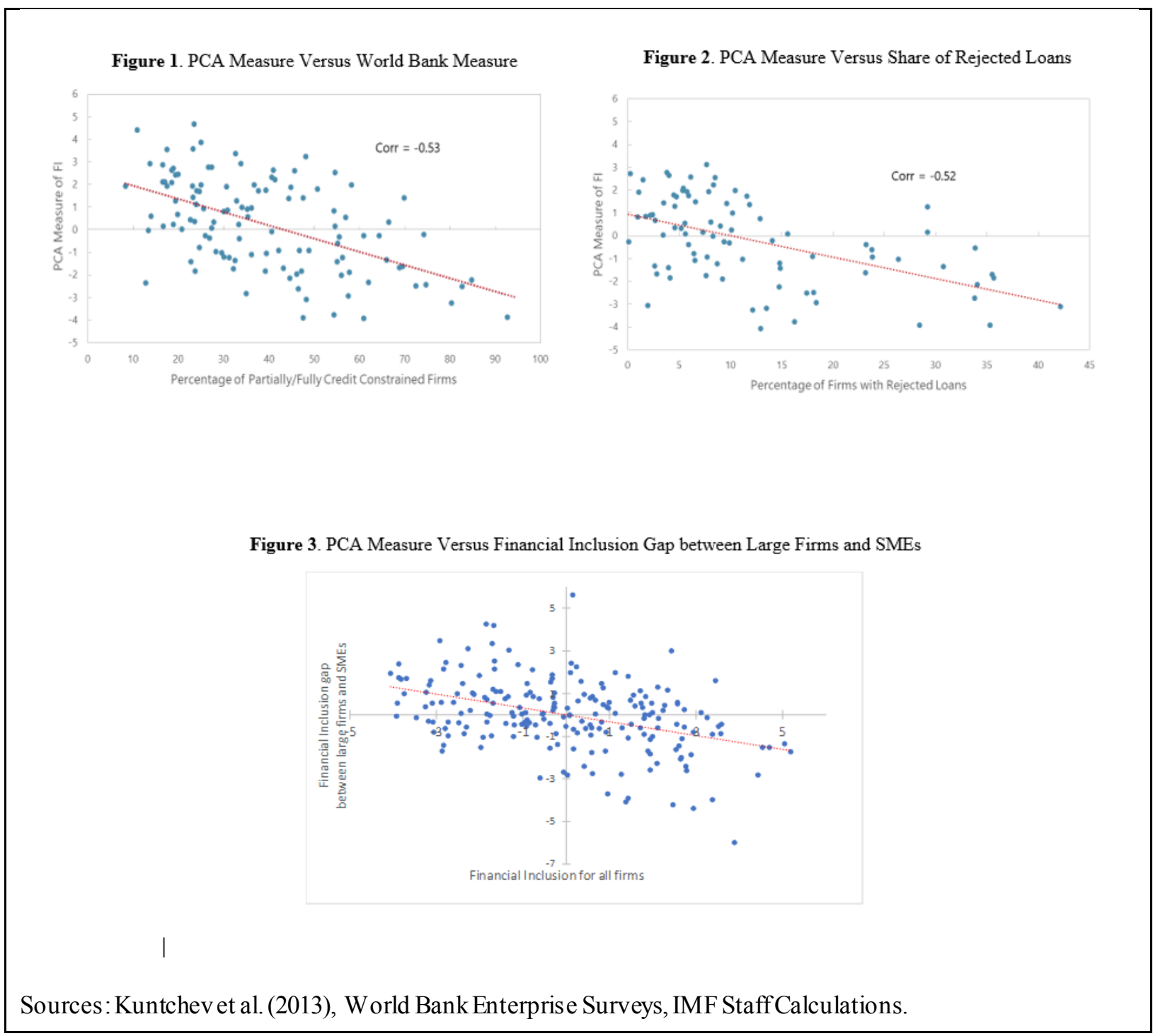


Figure 4. Output Gap Response to $100 \mathrm{bp}$ Nominal Interest Rate Figure 5. Output Gap Response to 100bp Nominal Interest Rate Tightening (Full Sample) Tightening (High SME Financial Inclusion)
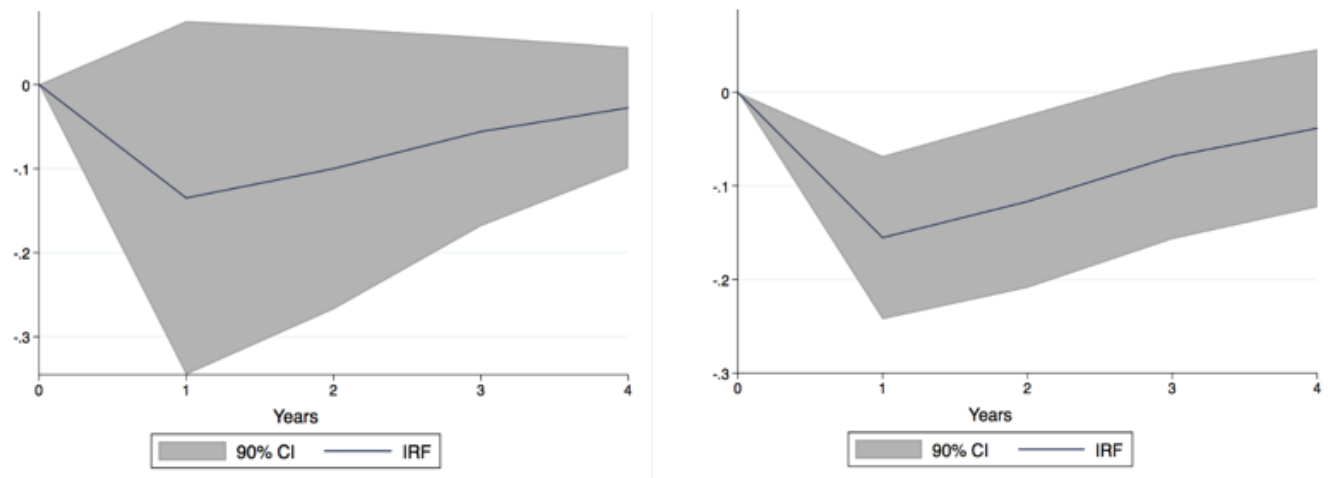

Figure 6. Output Gap Response to $100 \mathrm{bp}$ Nominal Interest Rate Tightening (Low SME Financial Inclusion)

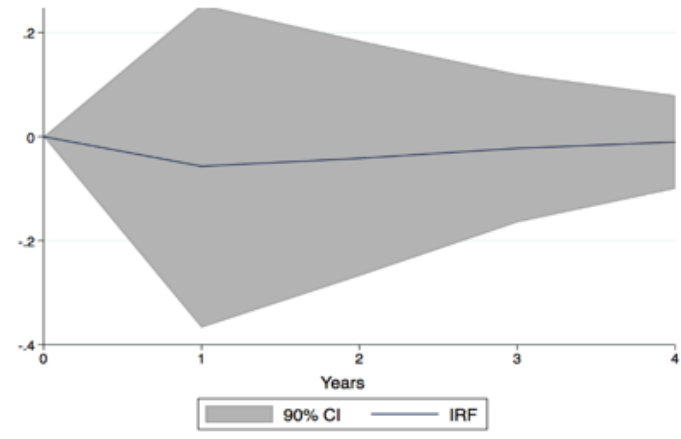

Figure 7. Ratio of Variances of Output and Inflation

SME FI and Achieving Price Stability

(Ratio of variances of output gap and inflation)

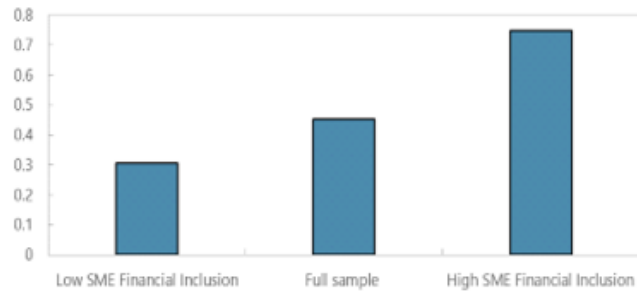




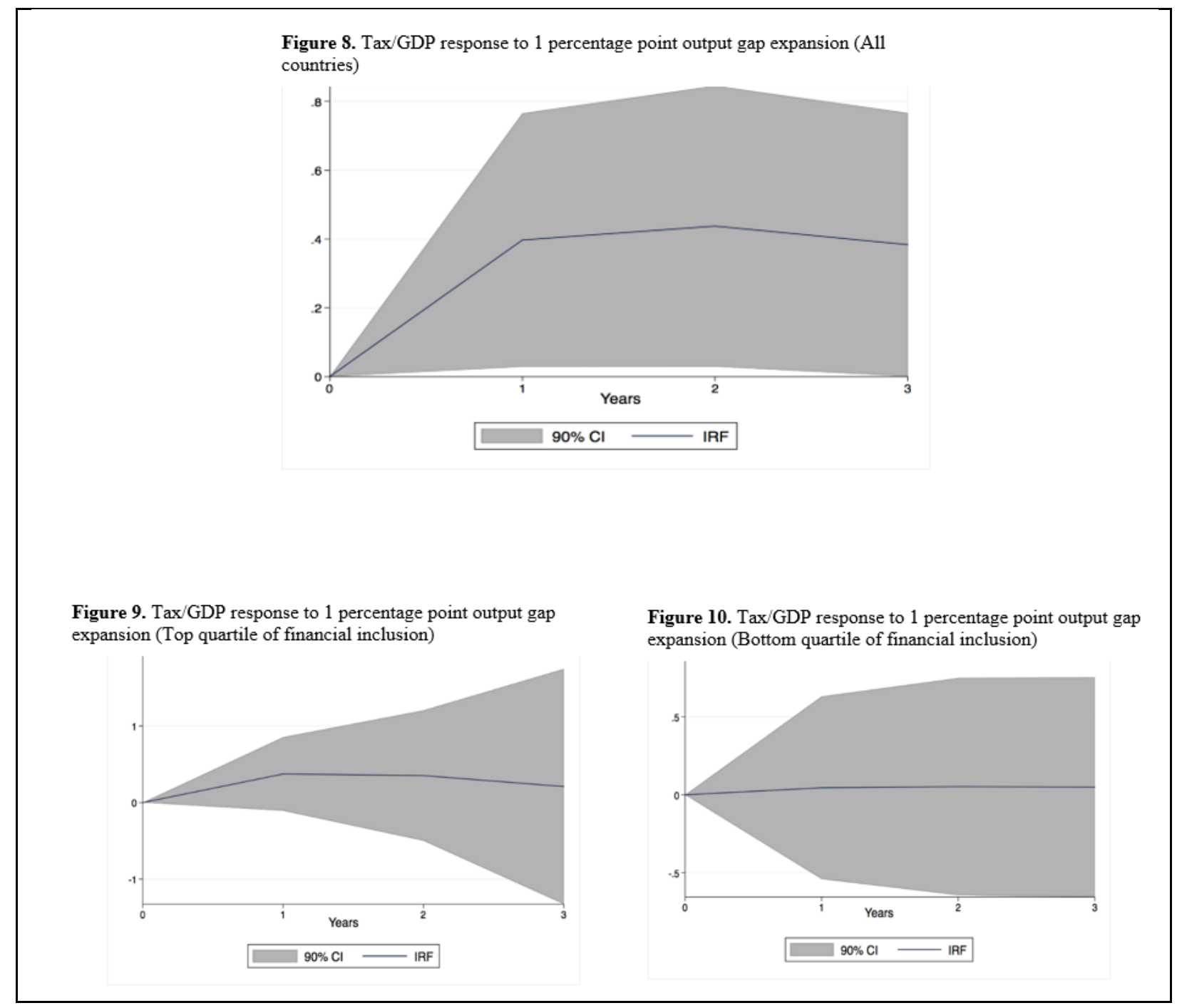




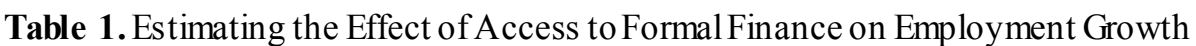

\begin{tabular}{|c|c|c|c|c|c|}
\hline $\begin{array}{l}\text { Dependent variable: employment growth } \\
\text { (percent) }\end{array}$ & All firms & $\begin{array}{c}\text { Large } \\
\text { firms } \\
(>100)\end{array}$ & $\begin{array}{l}\text { SMEs } \\
(<100)\end{array}$ & $\begin{array}{l}\text { Small } \\
(<20)\end{array}$ & $\begin{array}{l}\text { Medium } \\
(20-100)\end{array}$ \\
\hline \multirow[t]{2}{*}{ 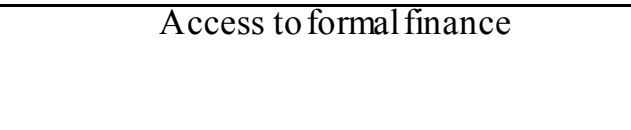 } & पा山 & 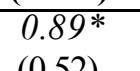 & पा1 & 向 & 西 \\
\hline & 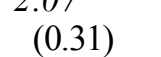 & Шயாய & 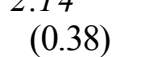 & एயா। & एणा। \\
\hline \multirow{2}{*}{ 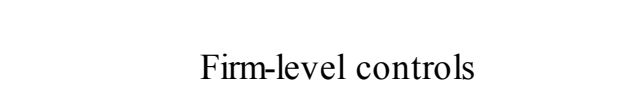 } & $\square$ & $\square$ & $\square$ & $\square$ & $\square$ \\
\hline & $\square \square \square$ & $\square \square \mathbb{Q}$ & $\square \square \mathbb{Q}$ & $\square \square \mathbb{Q}$ & $\square \square$ \\
\hline 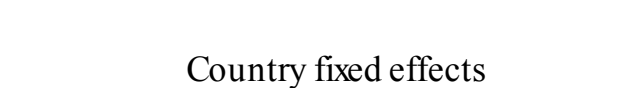 & $\begin{array}{l}\square \\
\square \square \square\end{array}$ & $\begin{array}{l}\square \\
\square \square \square\end{array}$ & $\begin{array}{l}\square \\
\square \square \square\end{array}$ & $\begin{array}{l}\square \\
\square \square \square\end{array}$ & $\square$ \\
\hline 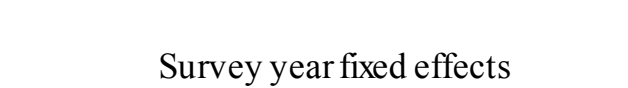 & $\begin{array}{l}\square \\
\square \square \square\end{array}$ & $\begin{array}{l}\square \\
\square \square \square\end{array}$ & $\begin{array}{c}\square \\
\square \square \square\end{array}$ & $\begin{array}{l}\square \\
\square \square \square\end{array}$ & $\begin{array}{l}\square \\
\square \square \square\end{array}$ \\
\hline $\begin{array}{c}\square \\
\mathrm{R}^{2} \square\end{array}$ & $\begin{array}{l}\square \\
\square[\square \square\end{array}$ & $\begin{array}{l}\square \\
\square[\square \square\end{array}$ & $\begin{array}{c}\square \\
\square\left[\begin{array}{ll}\square \\
\square \square\end{array}\right.\end{array}$ & $\begin{array}{c}\square \\
\square \square \square \square\end{array}$ & 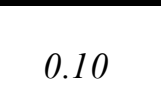 \\
\hline 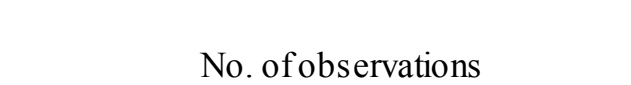 & $\begin{array}{l}\quad \square \\
\square \square \square \square \square\end{array}$ & $\begin{array}{c}\square \\
\square \square \square \square \square\end{array}$ & $\begin{array}{c}\square \\
\square[10 \square \square\end{array}$ & $\begin{array}{l}\square \\
\square \square \square \square \square\end{array}$ & $\begin{array}{l}\square \\
\square[\square \square \square\end{array}$ \\
\hline 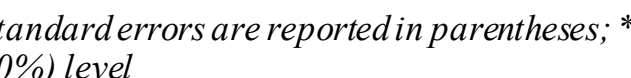 & 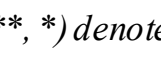 & & & & \\
\hline
\end{tabular}

$\square$

\begin{tabular}{|c|c|c|c|c|c|}
\hline $\begin{array}{l}\text { Dependent variable: labor productivity growth } \\
\text { (percent) }\end{array}$ & $\begin{array}{c}\text { All } \\
\text { firms }\end{array}$ & $\begin{array}{l}\text { Large } \\
\text { firms } \\
(>100)\end{array}$ & $\begin{array}{l}\text { SMEs } \\
(<100)\end{array}$ & $\begin{array}{l}\text { Small } \\
(<20)\end{array}$ & $\begin{array}{l}\text { Medium } \\
(20-100)\end{array}$ \\
\hline 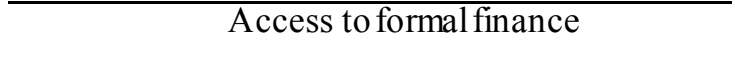 & $\begin{array}{l}\|\| \square \\
\square \| \square \square\end{array}$ & $\begin{array}{l}\square \| \square \\
\square \| \square \square\end{array}$ & 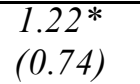 & 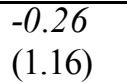 & 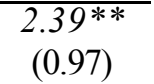 \\
\hline 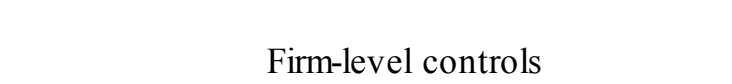 & $\begin{array}{l}\square \\
\square \square \square\end{array}$ & $\begin{array}{l}\square \\
\square \square \square\end{array}$ & $\begin{array}{l}\square \\
\square \square \square\end{array}$ & $\begin{array}{l}\square \\
\square \square \square\end{array}$ & $\begin{array}{l}\square \\
\square \square \square\end{array}$ \\
\hline 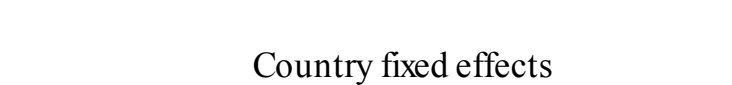 & $\begin{array}{l}\square \\
\square \square \square\end{array}$ & $\begin{array}{l}\square \\
\square \square \square\end{array}$ & $\begin{array}{l}\square \\
\square \square \square\end{array}$ & $\begin{array}{l}\square \\
\square \square \square\end{array}$ & $\begin{array}{l}\square \\
\square \square \square\end{array}$ \\
\hline 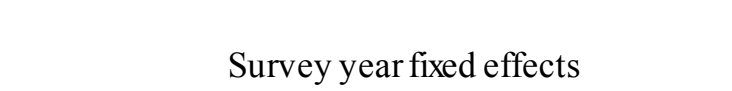 & $\begin{array}{l}\square \\
\square \square \square\end{array}$ & $\begin{array}{l}\square \\
\square \square \square\end{array}$ & $\begin{array}{l}\square \\
\square \square \square\end{array}$ & $\begin{array}{l}\square \\
\square \square \square\end{array}$ & $\begin{array}{l}\square \\
\square \square \square\end{array}$ \\
\hline $\mathrm{R}^{\square} \square$ & $\begin{array}{c}\square \\
\square[\square \square \square\end{array}$ & $\begin{array}{l}\square \\
\square \square \square\end{array}$ & $\begin{array}{l}\square \\
\square[\square \square\end{array}$ & $\begin{array}{c}\square \\
\square \pi \square \square\end{array}$ & $\begin{array}{l}\square \\
\square \pi \square \square\end{array}$ \\
\hline 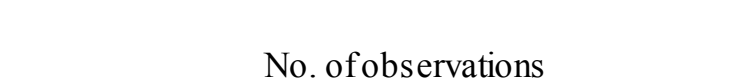 & $\begin{array}{c}\square \\
\square[\square \square \square\end{array}$ & $\begin{array}{c}\square \\
\square\left[\begin{array}{ll}\square \\
\square \square\end{array}\right.\end{array}$ & $\begin{array}{c}\square \\
\square\left[\begin{array}{ll}\square \\
\square \square\end{array}\right.\end{array}$ & $\begin{array}{l}\square \\
\square \square \square \square[\end{array}$ & $\stackrel{\square}{\square[\square \square \square}$ \\
\hline 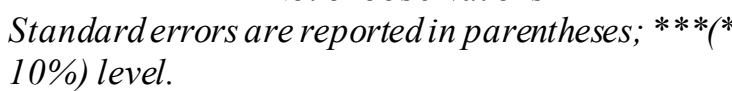 & 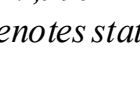 & |णा & $\square \square \square\|\| \square \square$ & 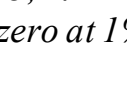 & $\square \square \square \square$ \\
\hline
\end{tabular}




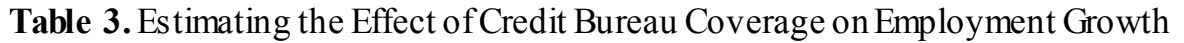

\begin{tabular}{|c|c|c|c|c|c|c|}
\hline $\begin{array}{l}\text { Dependent variable: employment growth } \\
\text { (percent) }\end{array}$ & All firms & $\begin{array}{l}\text { Large } \\
(>100)\end{array}$ & $\begin{array}{l}\text { SMEs } \\
(<100)\end{array}$ & $\begin{array}{c}\text { All } \\
\text { firms }\end{array}$ & $\begin{array}{l}\text { Large } \\
(<100)\end{array}$ & $\begin{array}{l}\text { SMEs } \\
(<100)\end{array}$ \\
\hline 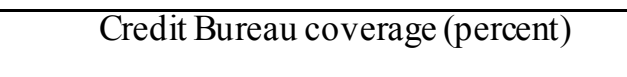 & $\frac{\pi}{2 \pi}$ & 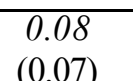 & 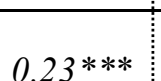 & 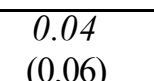 & 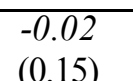 & 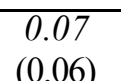 \\
\hline & एणाய & & एाता & & & Шயா \\
\hline 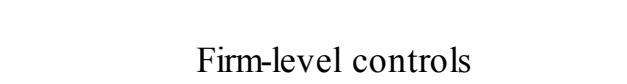 & $\begin{array}{l}\square \\
\square \square \square\end{array}$ & $\begin{array}{l}\square \\
\square \square \square\end{array}$ & $\begin{array}{l}\square \\
\square \square \square\end{array}$ & $\begin{array}{l}\square \\
\square \square \square\end{array}$ & $\begin{array}{l}\square \\
\square \square \square\end{array}$ & $\begin{array}{l}\square \\
\square \square \square\end{array}$ \\
\hline$\square$ & $\square$ & $\square$ & $\square$ & $\square$ & $\square$ & $\square$ \\
\hline 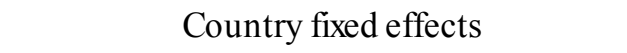 & $\square \square \square$ & $\square \square \|$ & $\square \square \square$ & $\square \square \square$ & $\square \square \square$ & $\square \square \square$ \\
\hline$\square$ & $\square$ & $\square$ & $\square$ & $\square$ & $\square$ & $\square$ \\
\hline 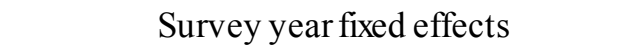 & $\square \square \square$ & $\square \square \square$ & $\square \square \square$ & $\square \square \square$ & $\square \square$ & $\square \square \square$ \\
\hline$\square$ & $\square$ & $\square$ & $\square$ & $\square$ & $\square$ & $\square$ \\
\hline $\mathrm{R}^{2} \square$ & $\square\left[\begin{array}{ll}\square \square \\
\end{array}\right.$ & $\square \square \square \square$ & $\square\left[\begin{array}{ll}\square \square \\
\end{array}\right.$ & $\square[\square \square \square$ & $\square \square \square \square$ & $\square\left[\begin{array}{ll}\square \square \\
\end{array}\right.$ \\
\hline$\square$ & $\square$ & $\square$ & $\square$ & $\square$ & $\square$ & $\square$ \\
\hline 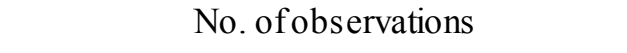 & 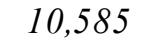 & 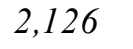 & $\square \square \square \square \square:$ & $\square \square \square \square \square$ & 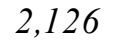 & $\square[\square \square[$ \\
\hline
\end{tabular}

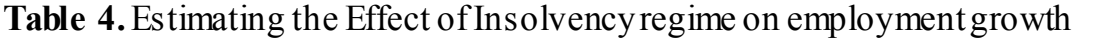

\begin{tabular}{|c|c|c|c|c|c|c|}
\hline $\begin{array}{l}\text { Dependent variable: employment } \\
\text { growth (percent) }\end{array}$ & $\begin{array}{c}\text { All } \\
\text { firms }\end{array}$ & $\begin{array}{l}\text { Large } \\
(>100)\end{array}$ & $\begin{array}{l}\text { SMEs } \\
(<\mathbf{1 0 0})\end{array}$ & $\begin{array}{c}\text { All } \\
\text { firms }\end{array}$ & $\begin{array}{l}\text { Large } \\
(<100)\end{array}$ & $\begin{array}{l}\text { SMEs } \\
(<100)\end{array}$ \\
\hline 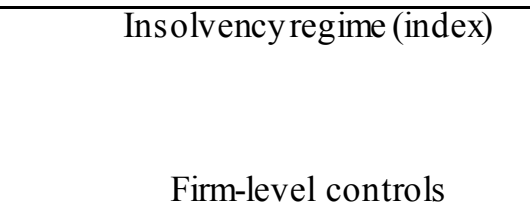 & 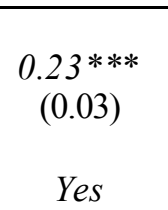 & 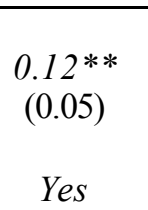 & 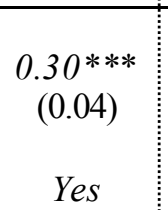 & 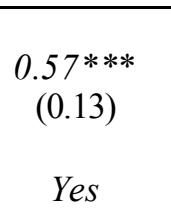 & 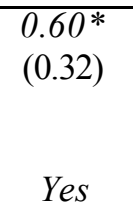 & 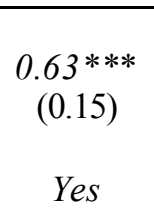 \\
\hline 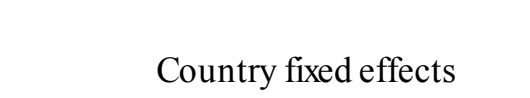 & $\begin{array}{l}\square \\
\square \square \square\end{array}$ & $\begin{array}{l}\square \\
\square \square \square\end{array}$ & $\begin{array}{c}\square \\
\square \square \square\end{array}$ & $\begin{array}{l}\square \\
\square \square \square\end{array}$ & $\square$ & $\begin{array}{c}\square \\
\square \square \square\end{array}$ \\
\hline 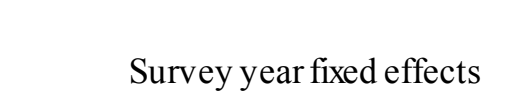 & $\begin{array}{c}\square \\
\square \square \square\end{array}$ & $\begin{array}{c}\square \\
\square \square \square\end{array}$ & $\begin{array}{c}\square \\
\square \square\end{array}$ & $\begin{array}{c}\square \\
\square \square \square\end{array}$ & $\begin{array}{l}\square \\
\square \square \square\end{array}$ & $\begin{array}{l}\square \\
\square \square\end{array}$ \\
\hline 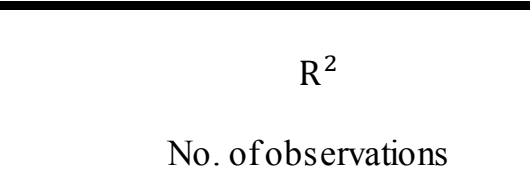 & 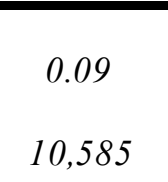 & $\begin{array}{c}\square \\
\square+\square \square \\
\square \\
\square \square \square \square\end{array}$ & $\begin{array}{c:}\square \\
\square \pi \square \square \\
\square \\
\square \square \square \square \square\end{array}$ & 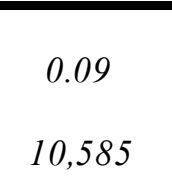 & $\begin{array}{c}\square \\
\square \square \square \square \\
\square \\
\square \square \square \square \square\end{array}$ & $\begin{array}{c}\square \\
\square \square \square \square \\
\square \\
\square[\square \square \square \square\end{array}$ \\
\hline
\end{tabular}




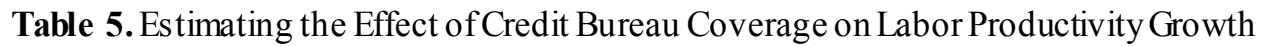

\begin{tabular}{|c|c|c|c|c|c|c|}
\hline $\begin{array}{l}\text { Dependent variable: labor productivity } \\
\text { growth (percent) }\end{array}$ & $\begin{array}{c}\text { All } \\
\text { firms }\end{array}$ & $\begin{array}{l}\text { Large } \\
(>100)\end{array}$ & $\begin{array}{l}\text { SMEs } \\
(<100)\end{array}$ & All firms & $\begin{array}{l}\text { Large } \\
(<100)\end{array}$ & $\begin{array}{l}\text { SMEs } \\
(<100)\end{array}$ \\
\hline \multirow[t]{4}{*}{ 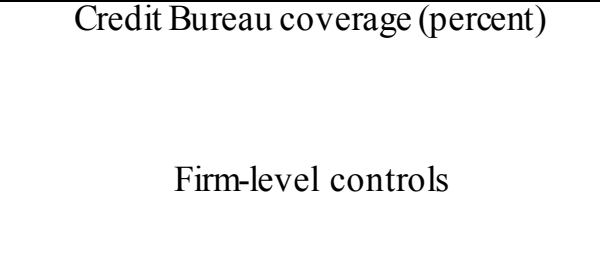 } & 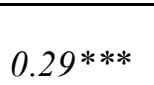 & $\begin{array}{c}\square \\
\square \pi \square \square\end{array}$ & 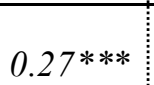 & 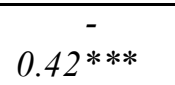 & 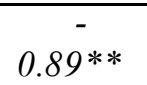 & 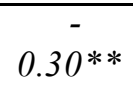 \\
\hline & पापाप & एाणाए & पाणाणा & एणाए & एणाण & एाणाण \\
\hline & $\square$ & $\square$ & $\square$ & $\stackrel{\square}{\square}$ & $\square$ & $\square$ \\
\hline & $\square$ & $\square$ & $\square$ & $\square$ & $\square$ & $\square$ \\
\hline 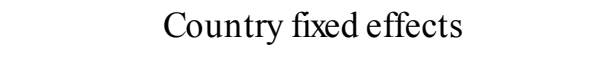 & $\square \square \square$ & $\square \square \square$ & $\square \square \square$ & $\square \square \square$ & $\square \square \square$ & $\square \square \square$ \\
\hline$\square$ & $\square$ & $\square$ & $\square$ & $\square$ & $\square$ & $\square$ \\
\hline 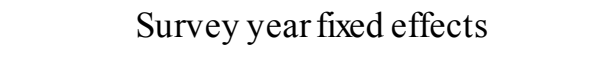 & $\square \square \square$ & $\square \square \square$ & $\square \square \square$ & $\square \square \square$ & $\square \square \mathbb{Q}$ & $\square \square \square$ \\
\hline$\square$ & $\square$ & $\square$ & $\square$ & $\square$ & $\square$ & $\square$ \\
\hline $\mathrm{R}^{2} \square$ & 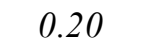 & 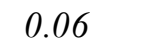 & $\square\left[\begin{array}{ll}\square \\
\end{array}\right.$ & $\square\left[\begin{array}{ll}\square \\
\end{array}\right.$ & $\square \square \square \square$ & $\square\left[\begin{array}{ll}\square \\
\end{array}\right.$ \\
\hline$\square$ & $\square$ & $\square$ & $\square$ & $\square$ & $\square$ & $\square$ \\
\hline 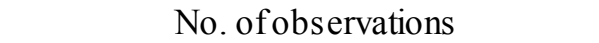 & पाणाएव & $\square\left[\begin{array}{ll}\square \\
0\end{array}\right.$ & 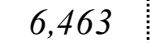 & $\square \square \square$ & 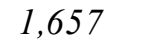 & 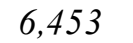 \\
\hline 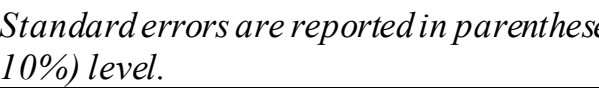 & 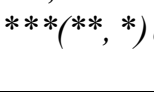 & 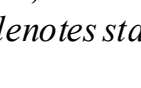 & 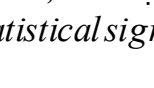 & 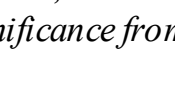 & 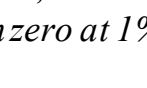 & $\square \square \square$ \\
\hline
\end{tabular}

$\square$

\begin{tabular}{|c|c|c|c|c|c|c|}
\hline \multicolumn{7}{|c|}{ 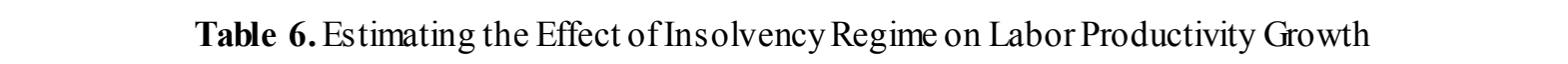 } \\
\hline $\begin{array}{l}\text { Dependent variable: labor productivity } \\
\text { growth (percent) }\end{array}$ & $\begin{array}{c}\text { All } \\
\text { firms }\end{array}$ & $\begin{array}{l}\text { Large } \\
(>100)\end{array}$ & $\begin{array}{l}\text { SMEs } \\
(<100)\end{array}$ & $\begin{array}{c}\text { All } \\
\text { firms }\end{array}$ & $\begin{array}{l}\text { Large } \\
(<100)\end{array}$ & $\begin{array}{l}\text { SMEs } \\
(<100)\end{array}$ \\
\hline 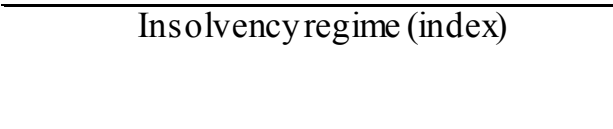 & 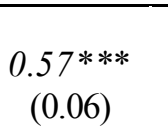 & 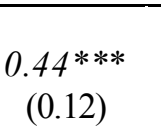 & 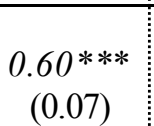 & 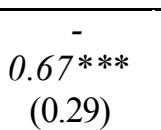 & 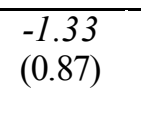 & 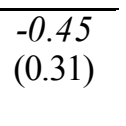 \\
\hline 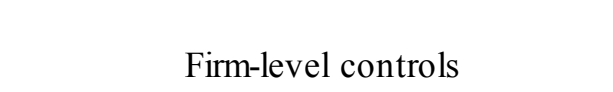 & $\begin{array}{l}\square \\
\square \square \square\end{array}$ & $\begin{array}{l}\square \\
\square \square \square\end{array}$ & $\begin{array}{l}\square \\
\square \square \square\end{array}$ & $\square$ & $\begin{array}{l}\square \\
\square \square \square\end{array}$ & $\begin{array}{l}\square \\
\square \square \square\end{array}$ \\
\hline 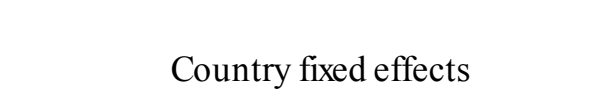 & $\square$ & $\square$ & $\square$ & $\square$ & $\square$ & $\begin{array}{l}\square \\
\square \square \square\end{array}$ \\
\hline 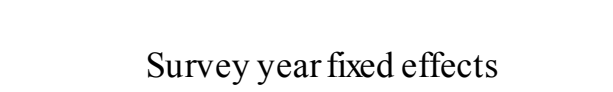 & $\begin{array}{l}\square \\
\square \square \square\end{array}$ & $\begin{array}{l}\square \\
\square \square \square\end{array}$ & $\begin{array}{l}\square \\
\square \square \square\end{array}$ & $\begin{array}{l}\square \\
\square \square \square\end{array}$ & $\begin{array}{l}\square \\
\square \square \square\end{array}$ & $\begin{array}{l}\square \\
\square \square \square\end{array}$ \\
\hline $\begin{array}{c}\square \\
\mathrm{R}^{2} \square\end{array}$ & $\begin{array}{c}\square \\
\square \mid \square \square \square\end{array}$ & 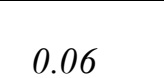 & 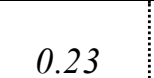 & 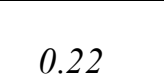 & 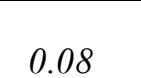 & $\begin{array}{l}\square \\
\square \ln \end{array}$ \\
\hline$\square$ & $\square$ & $\square$ & $\square$ & $\square$ & $\square$ & $\square$ \\
\hline 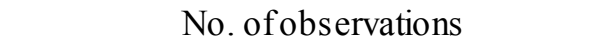 & $\square \square \square \square$ & $\square \square \square \square$ & $\square[\square \square \square:$ & 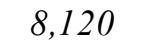 & 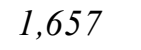 & 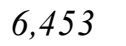 \\
\hline 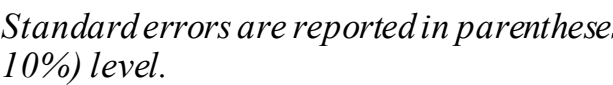 & 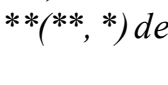 & 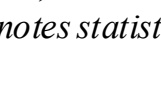 & 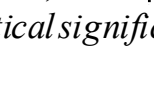 & 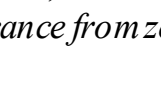 & 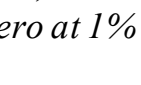 & पा口冋 \\
\hline
\end{tabular}

CInternational Monetary Fund. Not for Redistribution 
Figure 11. Employment Growth Gain from Moving to Advanced Economy Levels of Credit Bureau Coverage and Insolvency Regime

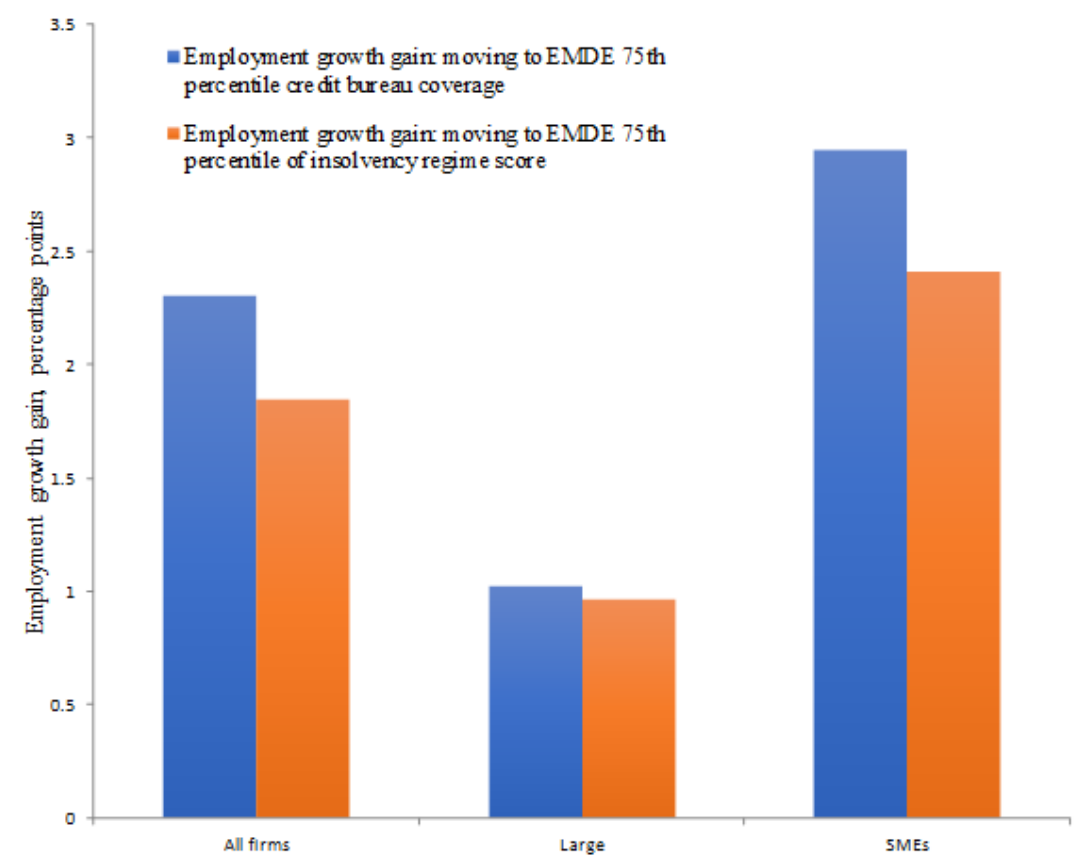

Figure 12. Labor Productivity Growth Gain from Moving to Advanced Economy Levels of Credit Bureau Coverage and Insolvency Regime

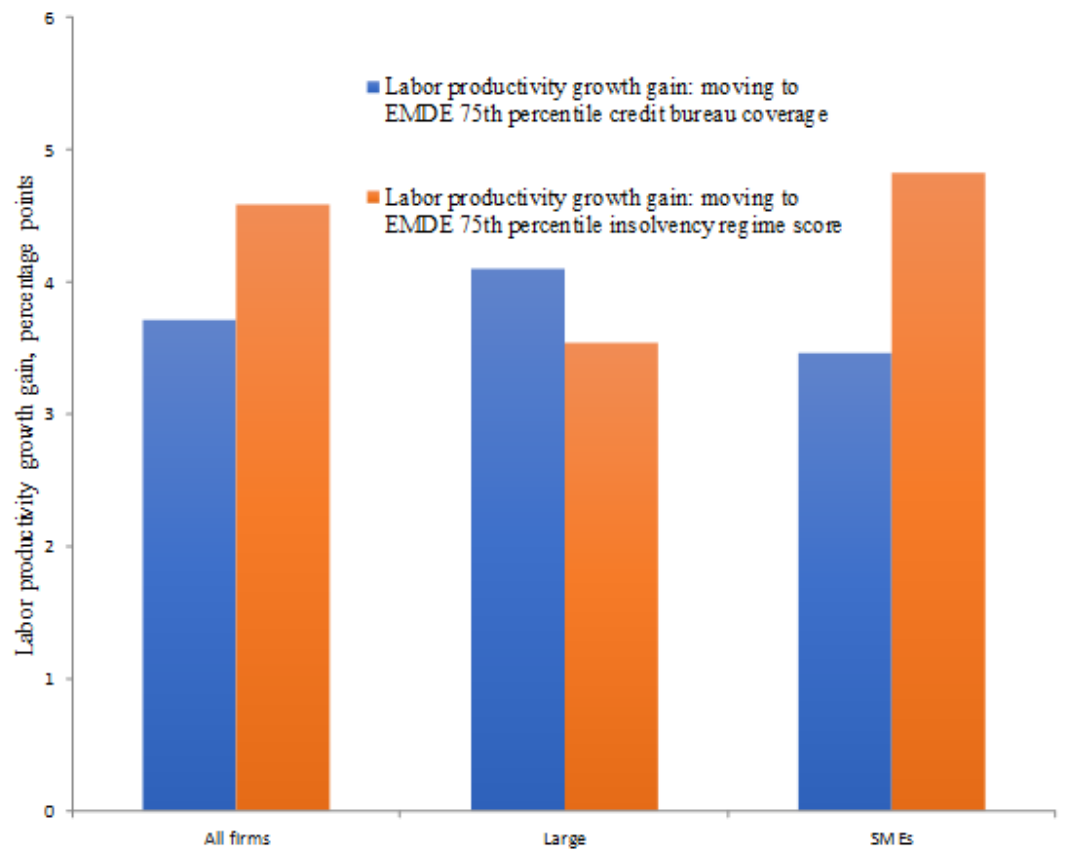


Figure 13. Probability Density Function (PDF) of the Share of SMEs in Total Lending (Middle East and Central Asia is MCD)

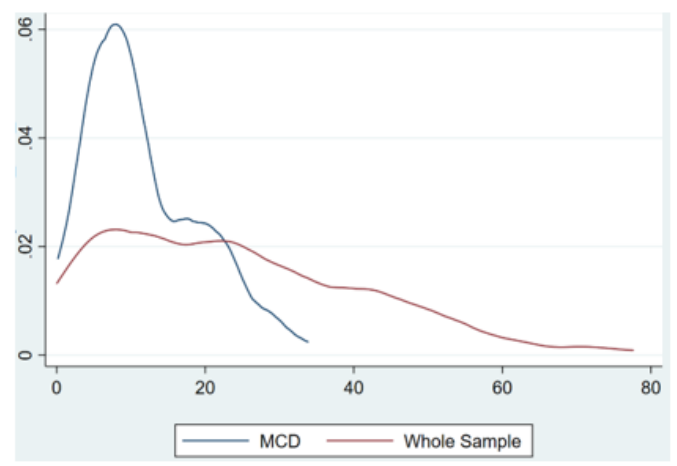

Figure 14. Trends of PDFs of Share of SMEs in Total Lending for Middle East and Central Asia countries

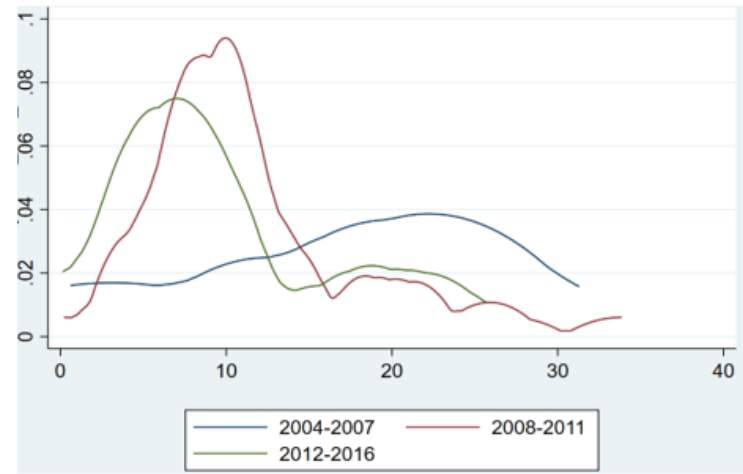

Figure 15. Trends of PDFs of Credit to Government and SOEs for Middle East and Central Asia Countries

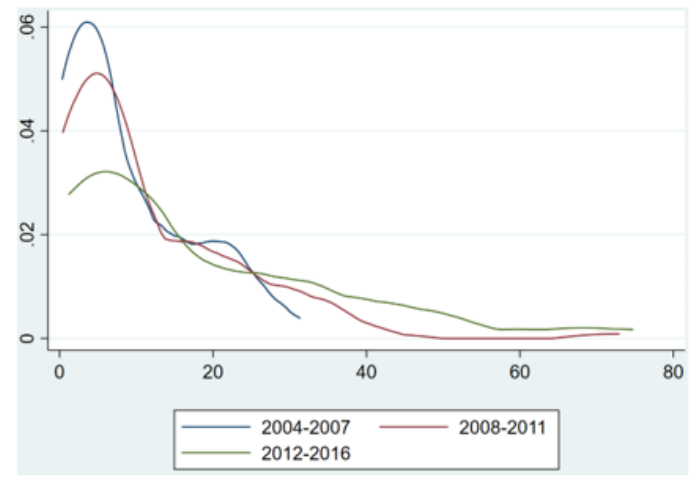




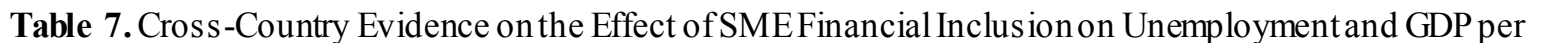

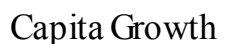

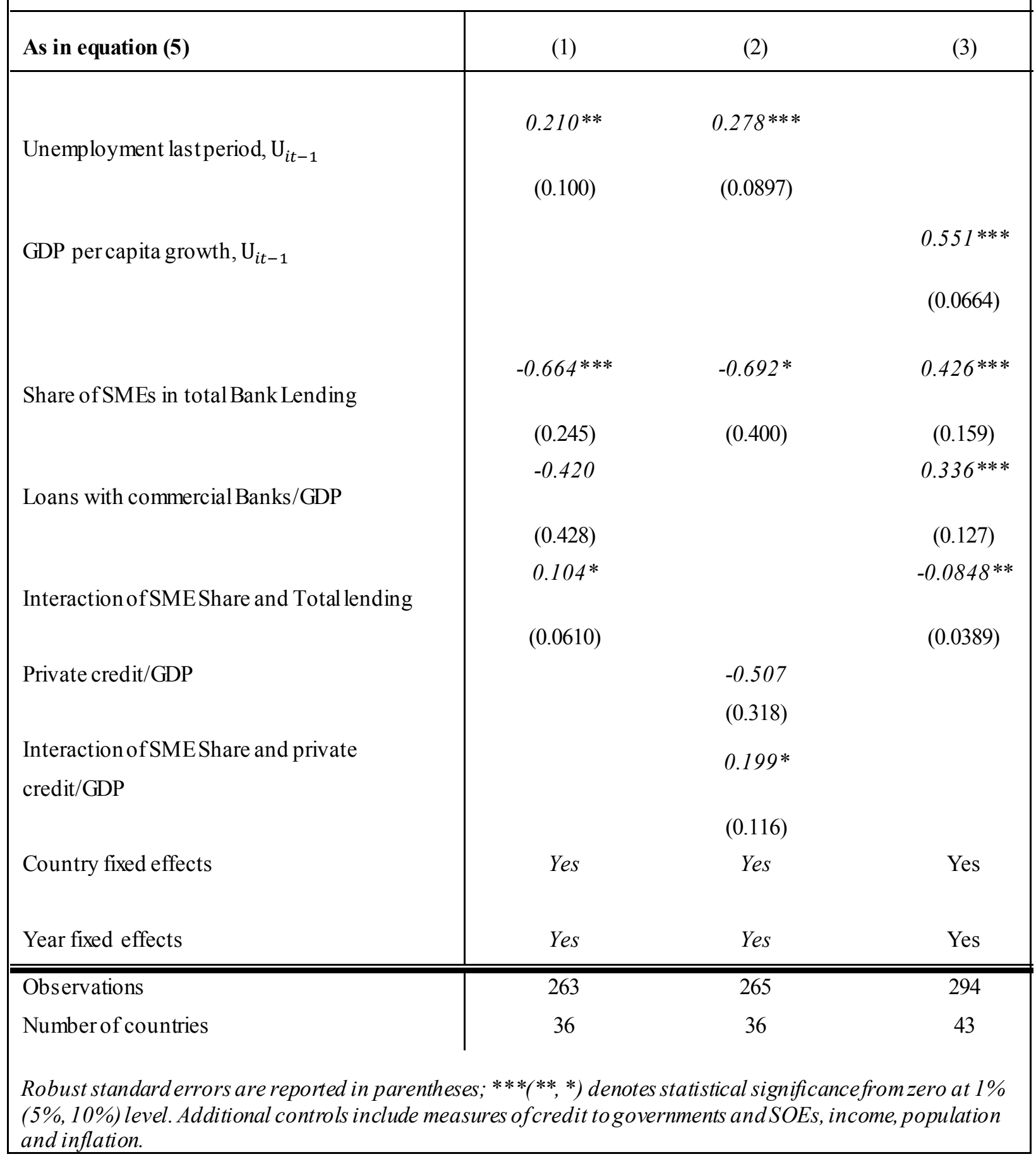

